\title{
Hrd1 suppresses Nrf2-mediated cellular protection during liver cirrhosis
}

\author{
Tongde Wu, ${ }^{1}$ Fei Zhao, ${ }^{1}$ Beixue Gao, ${ }^{2}$ Can Tan, ${ }^{2}$ Naoko Yagishita, ${ }^{3}$ Toshihiro Nakajima, ${ }^{3,4}$ \\ Pak K. Wong, ${ }^{5}$ Eli Chapman, ${ }^{1}$ Deyu Fang, ${ }^{2,6}$ and Donna D. Zhang ${ }^{1,6}$ \\ ${ }^{1}$ Department of Pharmacology and Toxicology, College of Pharmacy, The University of Arizona, Tucson, Arizona 85721, USA: \\ ${ }^{2}$ Department of Pathology, Northwestern University Feinberg School of Medicine, Chicago, Illinois 60611, USA; ${ }^{3}$ Institute of \\ Medical Science, St. Marianna University School of Medicine, Kawasaki 216-8511, Japan; ${ }^{4}$ Institution of Medical Science, Tokyo \\ Medical University, Tokyo 160-8402, Japan; ${ }^{5}$ Department of Aerospace and Mechanical Engineering, The University of Arizona, \\ Tucson, Arizona 85721, USA
}

Increased endoplasmic reticulum (ER) stress and reactive oxygen species (ROS) are the salient features of end-stage liver diseases. Using liver tissues from liver cirrhosis patients, we observed up-regulation of the XBP1-Hrd1 arm of the ER stress response pathway and down-regulation of the Nrf2-mediated antioxidant response pathway. We further confirmed this negative regulation of Nrf2 by Hrd1 using Hrd1 conditional knockout mice. Downregulation of Nrf2 was a surprising result, since the high levels of ROS should have inactivated Keap1, the primary ubiquitin ligase regulating Nrf2 levels. Here, we identified Hrd1 as a novel E3 ubiquitin ligase responsible for compromised Nrf2 response during liver cirrhosis. In cirrhotic livers, activation of the XBP1-Hrd1 arm of ER stress transcriptionally up-regulated $\mathrm{Hrd1}$, resulting in enhanced $\mathrm{Nrf} 2$ ubiquitylation and degradation and attenuation of the Nrf2 signaling pathway. Our study reveals not only the convergence of ER and oxidative stress response pathways but also the pathological importance of this cross-talk in liver cirrhosis. Finally, we showed the therapeutic importance of targeting Hrd1, rather than Keap1, to prevent Nrf2 loss and suppress liver cirrhosis.

[Keywords: Nrf2; Hrd1; liver cirrhosis]

Supplemental material is available for this article.

Received January 13, 2014; revised version accepted February 24, 2014.

Liver cirrhosis is a pathological state in which the normal liver tissue is replaced with scar tissue. Most commonly, liver cirrhosis is caused by alcohol consumption, viral hepatitis, chronic or excessive drug use, or exposure to hepatotoxic chemicals (Lotersztain et al. 2005; HernandezGea and Friedman 2011; Wynn and Ramalingam 2012). Currently, there are no effective treatments available to prevent or suppress the pathogenesis of liver cirrhosis. Therefore, understanding the molecular mechanisms underlying the pathological progression of liver cirrhosis and developing new therapeutic strategies for prevention or reversal of liver cirrhosis are urgently needed.

Studies suggest the involvement of endoplasmic reticulum (ER) stress in the pathogenesis of liver cirrhosis. Using experimental disease models, for example, it has been demonstrated that the ER is enlarged and stressed in response to intraperitoneal (IP) injection of carbon tetrachloride or by feeding a methionine- and choline-deficient diet (Mu et al. 2010; Zheng et al. 2011b; Wang et al. 2013). To cope with ER stress, mammalian cells

${ }^{6}$ Corresponding authors

Email dzhang@pharmacy.arizona.edu

E-mail fangd@northwestern.edu

Article published online ahead of print. Article and publication date are online at http://www.genesdev.org/cgi/doi/10.1101/gad.238246.114. have developed an adaptive mechanism called the unfolded protein response (UPR), signaled by three sensors residing on the ER membrane: IRE1, PERK, and ATF6 (Travers et al. 2000; Carvalho et al. 2006; Tsang et al. 2010). The cellular decisions in activating or coordinating these pathways are crucial in determining cell fate and disease outcome in a variety of pathological conditions (Tsang et al. 2010).

Hrd1, an E3 ubiquitin ligase sometimes called synoviolin, is a multipass ER membrane protein encoded by synovial apoptosis inhibitor 1 (SYVN1 or Hrd1). Recent studies have identified Hrd1 as a downstream effector of the IRE1 branch of the UPR. In response to ER stress, $X B P 1$ mRNA is spliced by IRE1 to produce $X B P 1 s$, which encodes an active transcription factor, resulting in transcriptional up-regulation of $\mathrm{Hrd} 1$ through a UPR element in its promoter (Yoshida et al. 2001; Yamamoto et al. 2008). Hrd1 is essential for embryogenesis, as demonstrated by the embryonic lethality of $\mathrm{Hrd1}^{-/-}$mice (Yagishita

(c) $2014 \mathrm{Wu}$ et al. This article is distributed exclusively by Cold Spring Harbor Laboratory Press for the first six months after the full-issue publication date (see http://genesdev.cshlp.org/site/misc/terms.xhtml). After six months, it is available under a Creative Commons License (Attribution-NonCommercial 4.0 International), as described at http:// creativecommons.org/licenses/by-nc/4.0/. 
et al. 2005). It also plays a crucial role in the pathogenesis of arthropathy and liver cirrhosis/fibrosis (Amano et al. 2003; Hasegawa et al. 2010). Although Hrd1 was initially characterized as an E3 ubiquitin ligase controlling ERassociated degradation (ERAD), recent reports demonstrate that Hrdl can also control the turnover of nonERAD substrates such as p53, IRE1, and Nrf1, a member of the cap'n'collar (CNC) transcription factor family (Yamasaki et al. 2007; Gao et al. 2008; Steffen et al. 2010; Tsuchiya et al. 2011).

In addition to the UPR, reactive oxygen species (ROS) have been shown to play a major role in the pathogenesis of liver cirrhosis (Lotersztajn et al. 2005; Wynn and Ramalingam 2012). Cellular ROS levels are regulated by the Nrf2 transcription factor that also belongs to the CNC family (Kensler et al. 2007; Jaramillo and Zhang 2013). Under basal conditions, Nrf2 levels are low due to tight regulation by Keap1, a substrate adaptor protein for the Cullin3 (Cul3)-based E3 ubiquitin ligase (Itoh et al. 1999; Kobayashi et al. 2004; Zhang et al. 2004). Activation of Nrf2 has been shown to confer protection against liver cirrhosis (Kawata et al. 2010; Ramani et al. 2012; Chen et al. 2013). Conversely, compromised Nrf2 signaling and elevation of ROS were detected in end-stage alcoholic liver disease (Kurzawski et al. 2012). Although the functional importance of the UPR and Nrf2 responses in liver cirrhosis has recently emerged, the interplay between these two major stress response pathways during the pathogenesis of liver cirrhosis remains unclear. Using liver tissues from cirrhosis patients, we detected upregulation of the XBP1-Hrdl arm of the ER stress pathway and down-regulation of the Nrf2-mediated antioxidant response. Here, we demonstrate that these two stress response pathways converge, and therapeutic modulation through inhibition of the IRE1-XBP1-Hrd1 pathway can prevent loss of the Nrf2-mediated protection, thus mitigating liver cirrhosis in vivo.

\section{Results}

The XBP1-Hrd1 arm of the ER stress pathway is upregulated, and the Nrf2-mediated antioxidant response pathway is down-regulated in human cirrhotic livers

To investigate the role of the ER and Nrf2-mediated stress responses in the pathogenesis of liver cirrhosis, we measured the protein expression of several key proteins involved in both pathways in human cirrhotic liver tissues. Immunohistochemistry (IHC) and immunoblot analyses of cirrhotic liver tissues revealed increased levels of XBP1s and Hrd1 proteins that corresponded to compromised Nrf2 signaling, as evidenced by the decreased protein levels of Nrf2 and Nrf2-regulated proteins, NQO1, and GCLM (Fig. 1A,B). Consistently, the mRNA level of $H R D 1$ was increased, whereas mRNA levels of Nrf2 target genes, such as NQO1 and GCLM, were decreased in cirrhotic tissues compared with normal tissues (Fig. 1C). In contrast, no change in NRF2 mRNA expression was observed (Fig. 1C), indicating that Hrdl is altered at the transcriptional level, while Nrf2 is regulated at the post-transcriptional level during cirrhosis. These results demonstrate an up-regulation of the XBP1-Hrd1 arm of the ER stress response pathway and a down-regulation of the Nrf2 antioxidant response pathway in liver tissues from end-stage alcoholic cirrhosis patients. To further confirm this, we used a murine $\mathrm{CCl}_{4}$-induced liver cirrhosis model. The protein levels of XBP1s and Hrd1 were increased in cirrhotic liver tissues from both $\mathrm{Nrf2}^{+/+}$and $\mathrm{Nrf2}^{-/-}$mice (Fig. 1D,E), suggesting activation of the XBP1-Hrd1 pathway during the course of liver cirrhosis. Interestingly, the protein levels of Nrf2, GCLM, and NQO1 decreased in cirrhotic livers, and altered expression of GCLM and NQO1 was Nrf2-dependent, since no changes in their expression were detected in $\mathrm{Nrf2}^{-/-}$mice (Fig. 1D,E). Similar to the results obtained using human specimens, the mRNA level of $\mathrm{Hrd1}$ increased in $\mathrm{CCl}_{4}$-treated groups regardless of genotype, whereas the mRNA levels of $\mathrm{Nrf2}$ (in $\mathrm{Nrf2}^{+/+}$ mice) and Keap1 were not affected by $\mathrm{CCl}_{4}$ treatment (Fig. 1F). In contrast, the mRNA levels of NQO1 and GCLM decreased in $\mathrm{Nrf2}^{+/+}$but not $\mathrm{Nrf2}^{-/-}$mice (Fig. 1F). This inverse activation status of the XBP1-Hrd1 and Nrf2 pathways observed in human and mouse cirrhotic livers prompted us to test whether there is cross-talk between these two pathways using Hrd1 conditional knockout mice. Hrd1 was deleted through tail vein injection of adenoviruses containing Cre recombinase. Silencing of $\mathrm{Hrd1}$, which occurred only in $\mathrm{Hrd1} 1^{\mathrm{f} / \mathrm{f}}$ but not $\mathrm{Hrd1} 1^{+/+}$ mice, resulted in a robust increase in the protein level of Nrf2, NQO1, and GCLM as well as an increase in the mRNA level of NQO1 and GCLM without changing Nrf2 or Keap1 (Fig. 1G-I).

\section{XBP1s and Nrf2 expression levels are inversely correlated}

Next, using cultured cells, we investigated the inverse correlation between the activation of the XBP1-Hrd1 pathway and the Nrf2 pathway and the underlying molecular mechanism of their negative correlation. Overexpression of XBP1s decreased the protein level of Nrf2 under both basal (untreated) and induced (tertbutylhydroquinone [tBHQ]-treated) conditions (Fig. 2A) in both HEK293T (Fig. 2A) and MDA-MB-231 (data not shown) cells. Overexpression of XBP1s also reduced the expression of NQO1, GCLM, and HO-1 but not Keap1 (Fig. 2A). Ectopic expression of XBP1s decreased AREluciferase activity in a dose-dependent manner under both basal and induced conditions (Fig. 2B) and also decreased the mRNA levels of NQO1 and HO-1 without affecting NRF2 or KEAP1 (Fig. 2C). Next, we used $X B P 1^{+/+}$ and $X B P 1^{-1-}$ mouse embryonic fibroblast (MEF) cells to confirm these observations. Cell status was validated by the absence of both unspliced XBP1 (XBP1u) and XBP1s in $X B P 1^{-1-}$ cells (Fig. 2D). The protein levels of Nrf2, HO-1, and GCLM were higher in $X B P 1^{-/-}$than in $X B P 1^{+/+}$cells (Fig. 2E), as were the mRNA levels of NQO1, GCLM, and HO-1 but not Nrf2 (Fig. 2F). Increased expression of NQO1 and GCLM in $X B P 1^{-1-}$ cells was found to correlate with enhanced activities of NQO1 (Fig. 2G) and a higher level of glutathione under both basal and induced conditions in 
Wu et al.

A

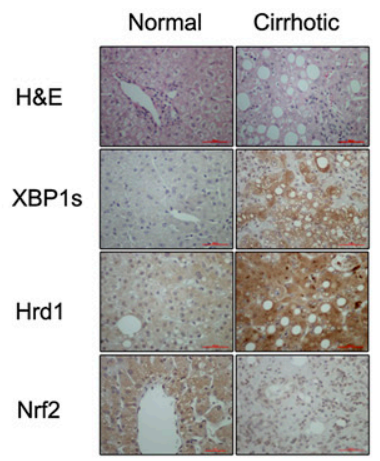

B

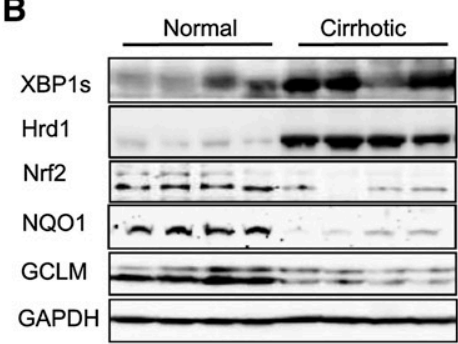

C

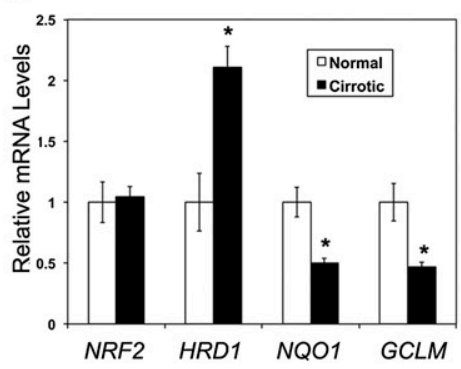

D

H\&E
Hrd1
Nrf2
GCLM

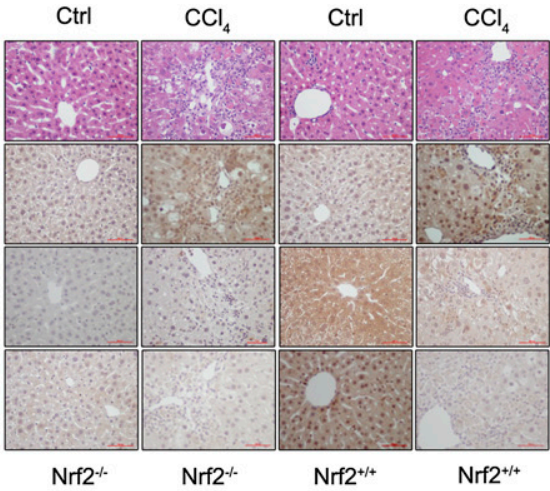

E

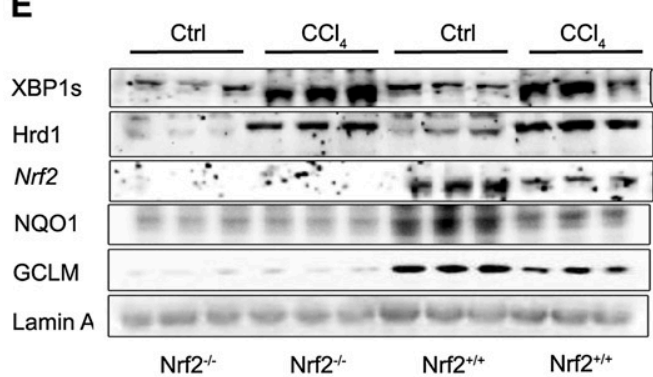

F

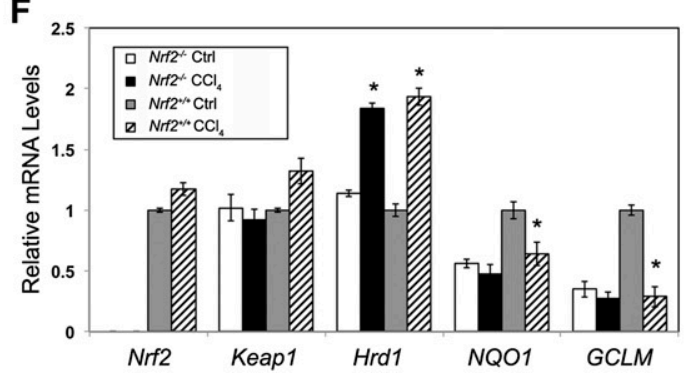

G

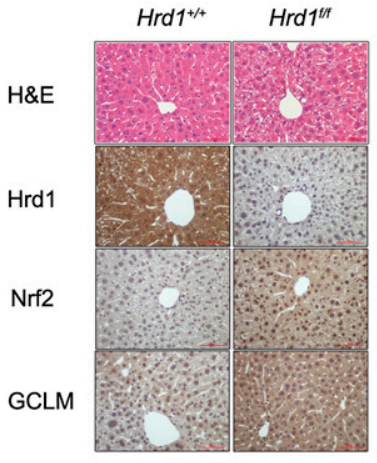

H

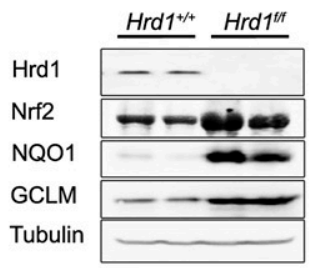

I

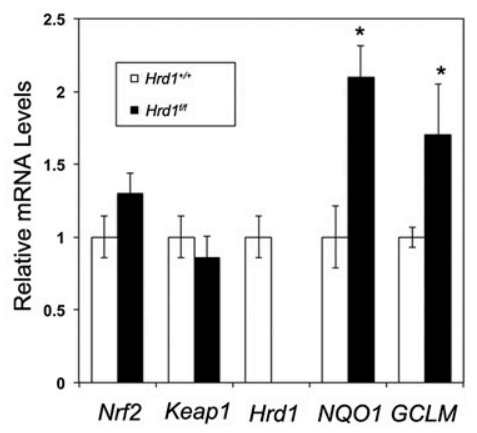

Figure 1. The XBP1-Hrd1 arm of the ER stress pathway is up-regulated, and the Nrf2-mediated antioxidant response pathway is downregulated in human cirrhotic liver. $(A-C)$ Normal or cirrhotic liver tissues from patients with end-stage liver cirrhosis. $(A)$ Representative hematoxylin and eosin (H\&E) and IHC staining of XBP1s, HRD1, and NRF2 from liver tissues. $(B)$ Expression levels of the indicated proteins detected using immunoblot analysis. $(C)$ mRNA levels of NRF2, HRD1, NQO1, and GCLM measured by quantitative real-time PCR (qRT-PCR). (D-F) Liver tissues from control or $\mathrm{CCl}_{4}$-treated mice. $(D)$ Representative $\mathrm{H} \& \mathrm{E}$ and IHC staining of Hrd1, Nrf2, and GCLM from liver tissues. $(E)$ Expression levels of the indicated proteins detected using immunoblot analysis. $(F)$ mRNA levels of Nrf2, Keap1, Hrd1, NQO1, and GCLM measured by qPCR. (G-I) Liver tissues from $H r d 1^{+/+}$and $H r d 1^{\text {f/f }}$ mice tail veininjected with Cre-containing viruses for $5 \mathrm{~d}$. $(G)$ Representative H\&E and IHC staining of Hrd1, Nrf2, and GCLM from liver tissues. (H) Expression levels of the indicated proteins detected using immunoblot analysis. (I) mRNA levels of Nrf2, Keap1, Hrd1, NQO1, and $G C L M$ measured by qPCR. For immunoblot analysis, each lane contains a tissue lysate from an individual person $(B)$ or mouse $(E, H)$. For qRT-PCR, results are expressed as means $\pm \mathrm{SD} ; n=4$, four people per group $(C) ; n=4$, three mice per group $(F)$; and $n=3$, three mice per group $(I)$.

$X B P 1^{-1-}$ cells (Fig. 2H). It is notable that more prominent differences were observed under induced conditions (Fig. $2 \mathrm{~A}-\mathrm{C}, \mathrm{E}-\mathrm{H})$. Furthermore, the higher Nrf2 protein level in $X B P 1^{-1-}$ cells was due to a longer half-life of the Nrf2 protein in $\mathrm{XBP1}^{-/-}$cells (40.5 min vs. $19.8 \mathrm{~min}$ in $\mathrm{XBP1}^{-/-}$ and $X B P 1^{+/+}$cells, respectively) (Fig. 2I).

\section{Nrf2 is negatively regulated by Hrd1}

Next, we explored the relationship between Hrd1, a newly identified XBP1s target gene, and Nrf2. Similar to the $\mathrm{XBP} 1$ results, overexpression of Hrd1 reduced the protein level of Nrf2, GCLM, and HO-1 (Fig. 3A), whereas siRNAmediated silencing of $\mathrm{Hrd} 1$ enhanced these proteins (data not shown). In accordance with these results, expression of Nrf2, GCLM, and HO-1 was much higher in $\mathrm{Hrd1}^{-/-}$ compared with $\mathrm{Hrd1}^{+/+}$cells (Fig. 3B). mRNA expression of HO-1 was also higher in $\mathrm{Hrd1}^{-/-}$cells (Fig. 3C). Furthermore, Nrf2 protein was more stable with a longer half-life in $\mathrm{Hrd1}^{-/-}$compared with $\mathrm{Hrd}^{+/+}$cells $(39.7 \mathrm{~min}$ vs. $16.3 \mathrm{~min}$ ) (Fig. 3D). Since Hrd1 is an E3 ubiquitin ligase, we tested the possibility that Hrdl ubiquitylates Nrf2. Overexpression of Hrd1 enhanced Nrf2 ubiquitylation, as shown in a cell-based ubiquitylation analysis (Fig. 
A

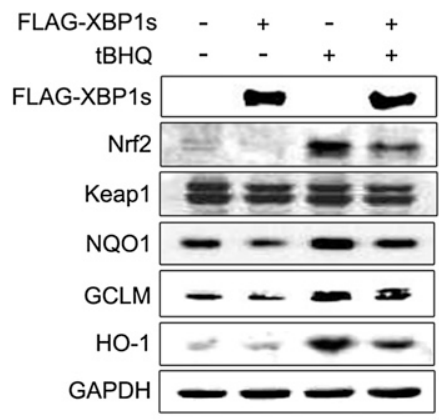

B

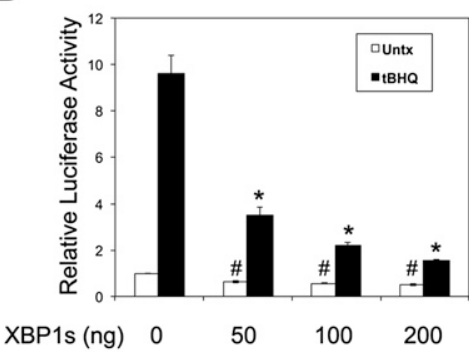

C

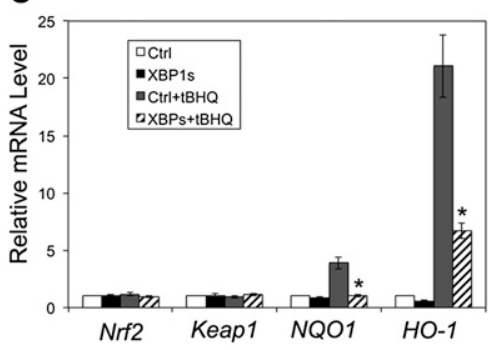

D

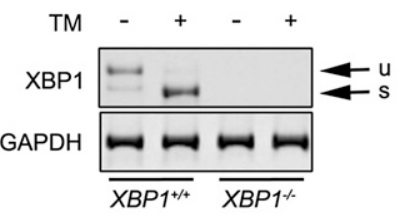

E
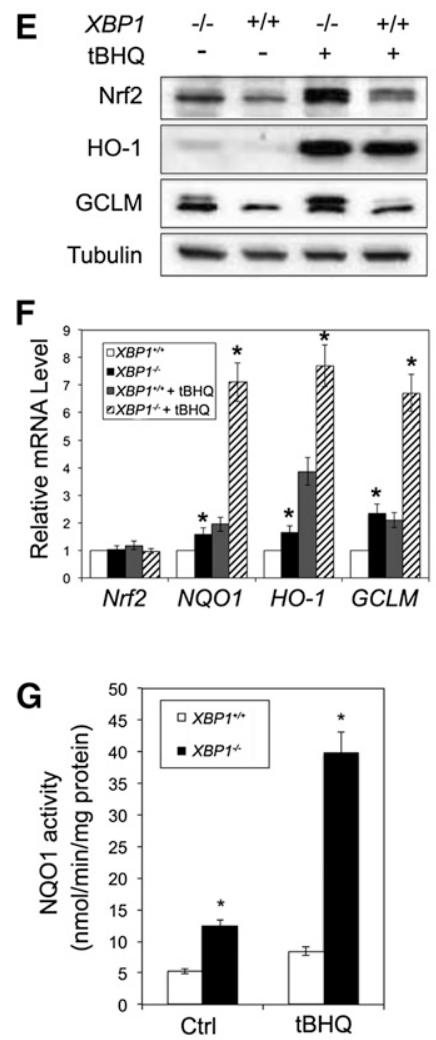

H
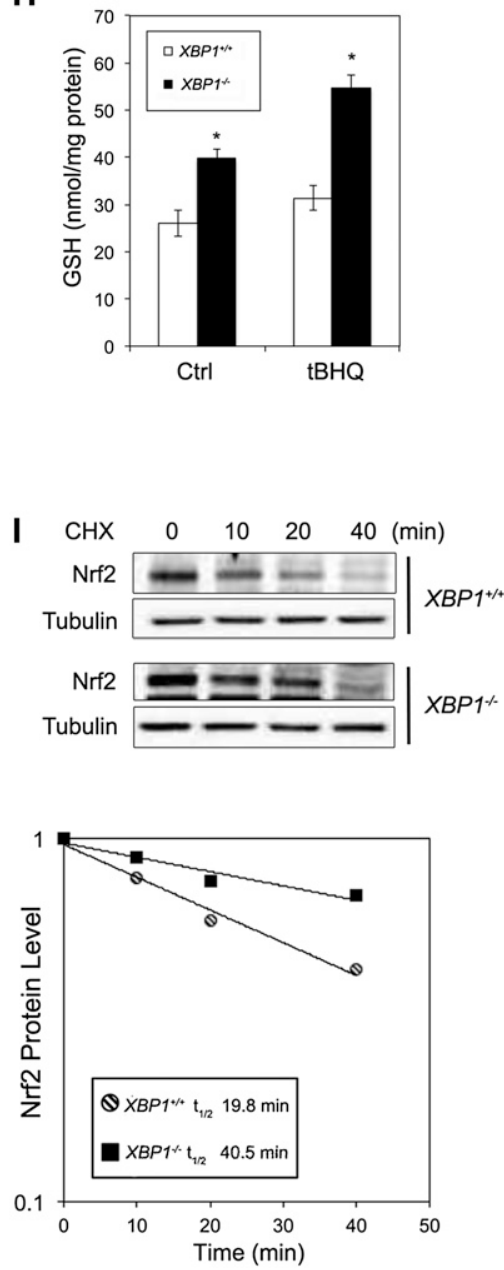

Figure 2. XBP1s and Nrf2 expression levels are inversely correlated. (A) Immunoblot analysis of the indicated proteins with cell lysates from HEK293T cells transfected with an empty vector or Flag-XBP1s. At $24 \mathrm{~h}$ post-transfection, cells were left untreated or treated with $50 \mu \mathrm{M}$ tBHQ for $16 \mathrm{~h}$. (B) Luciferase activities were measured in HEK293T cells cotransfected with NQO1-ARE-firefly luciferase and TK-Renilla luciferase along with the indicated amount of Flag-XBP1s for $36 \mathrm{~h}$. Relative luciferase activities and SDs were calculated from three independent experiments $(n=3) .(C)$ mRNA levels of Nrf2, Keap1, NQO1, and HO-1 in HEK293T cells transfected and treated as described in $A(n=3$ independent experiments). (D) Splicing analysis of XBP1 mRNA (unspliced [u] and spliced [s]) was performed as described in the Materials and Methods. Total mRNA was extracted from $X B P 1^{+/+}$and $X B P 1^{-/-}$MEF cells untreated or treated with $5 \mu \mathrm{g} / \mathrm{mL}$ tunicamycin for $16 \mathrm{~h}$. $(E-H)$ Protein levels of the indicated proteins $(E)$, mRNA levels of the indicated genes $(F)$, NQO1 activities $(G)$, and intracellular glutathione levels $(H)$ were measured in $X B P 1^{+/+}$and $X B P 1^{-/-}$MEF cells left untreated or treated with $50 \mu \mathrm{M}$ tBHQ for $16 \mathrm{~h}$. (I) The Nrf2 protein half-life in $X B P 1^{+/+}$and $X B P 1^{-/-}$MEF cells was measured in the presence of $50 \mu \mathrm{M}$ cycloheximide at the indicated time points. Cell lysates were subjected to immunoblot analysis, with Nrf2 intensity normalized to tubulin plotted using a semilogarithmic scale.

3E). In addition, coexpression of cyan fluorescent protein (CFP)-Hrd1 and red fluorescent protein (RFP)-Nrf2 showed that in the perinuclear clusters where Hrd1 localized, the Nrf2 signal was reduced (appeared as holes in the RFP channel), suggesting that ectopically expressed Hrd1 down-regulated Nrf2 (Fig. 3F). This inverse colocalization pattern was diminished by MG132 treatment $(80 \%$ vs. $20 \%$ in untreated and MG132-treated cells, respectively) (Fig. 3F). These results suggest that Hrdl ubiquitylates Nrf2.

To further confirm that XBP1-mediated down-regulation of the Nrf2 signaling pathway is through Hrd1, several additional experiments were performed. First, overexpression of XBP1s, but not the unspliced mutant XBP1-3K/3R (XBP1u), up-regulated Hrd1 and decreased Nrf2, NQO1, GCLM, and HO-1 under both basal and induced conditions (Fig. 4A). Second, the XBP1s-mediated down-regulation of Nrf2 signaling was blunted by transfection of Hrd1-siRNA (Fig. 4B). Third, a decreased Nrf2 expression by XBP1s overexpression was observed only in $\mathrm{Hrd}^{+/+}$but not in $\mathrm{Hrd}^{-/-}$cells (Fig. 4C). Fourth, upregulation of endogenous $\mathrm{XBP} 1 \mathrm{~s}$ induced by tunicamycin also decreased Nrf2, NQO1, and GCLM (Fig. 4D). Finally, the mRNA levels of Hrd1 and HO-1 were inversely 
Wu et al.

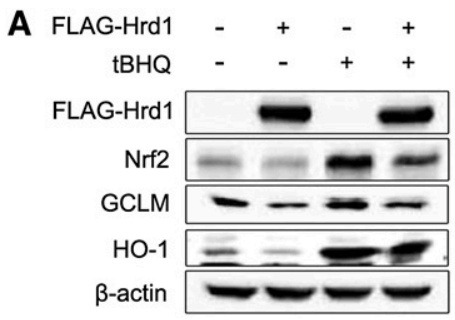

B

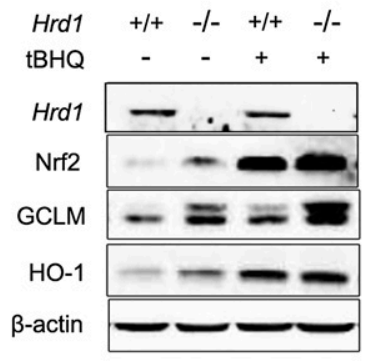

C

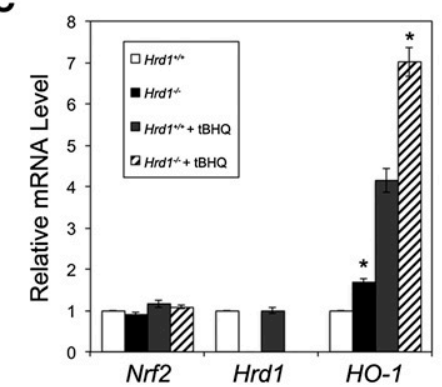

D
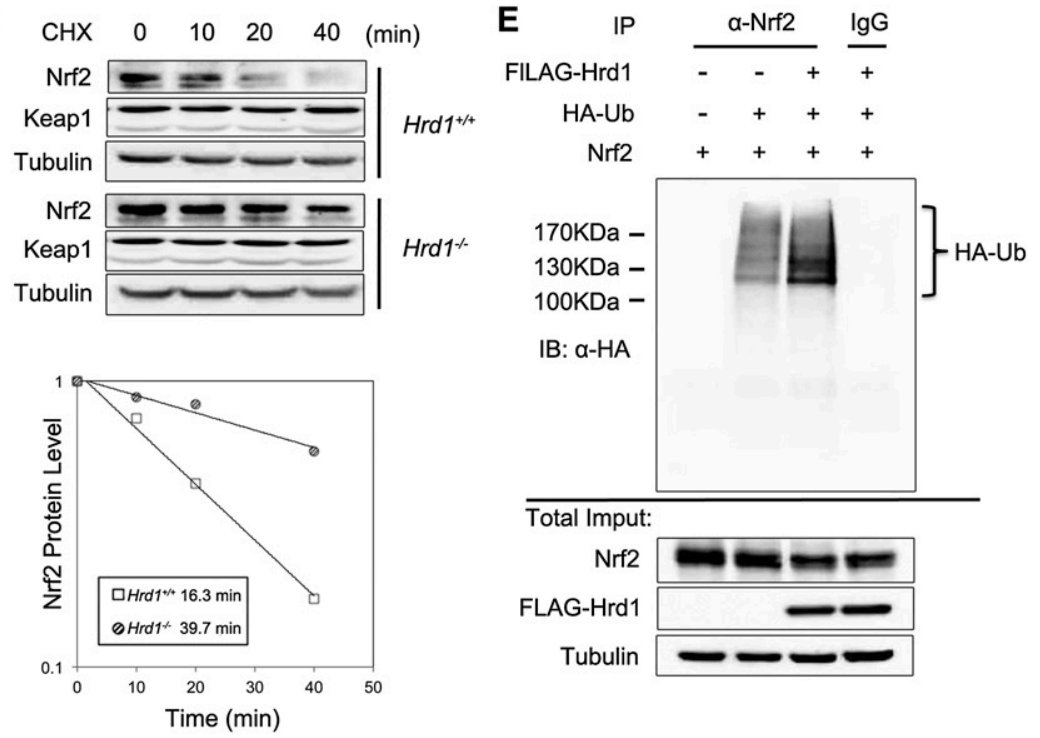

Total Imput:

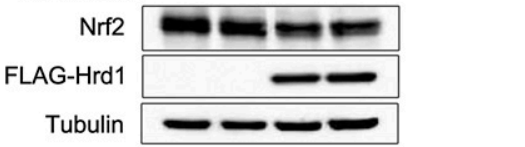

$\mathbf{F}$

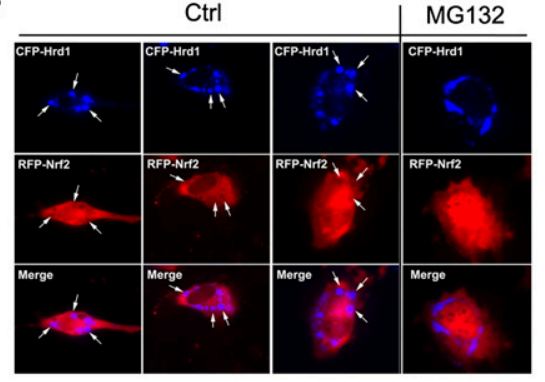

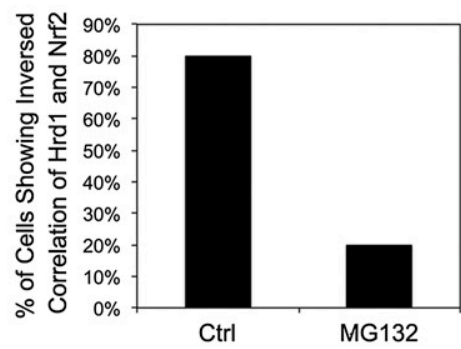

Figure 3. Nrf2 is negatively regulated by Hrd1. (A) Immunoblot analysis of the indicated proteins with cell lysates from HEK293T cells transfected with an empty vector or Flag-Hrd1. At $24 \mathrm{~h}$ post-transfection, cells were left untreated or treated with $50 \mu \mathrm{M}$ tBHQ for $16 \mathrm{~h}$. $(B, C)$ Protein levels of the indicated proteins $(B)$ and mRNA levels of the indicated genes $(C)$ were measured in $\mathrm{Hrd1} 1^{+/+}$and $\mathrm{Hrd1} 1^{-/-}$ MEF cells left untreated or treated with $50 \mu \mathrm{M}$ tBHQ for $16 \mathrm{~h} .(D)$ The Nrf2 protein half-life in $\mathrm{Hrd1} 1^{+/+}$and $\mathrm{Hrd1} 1^{-/-}$MEF cells was measured as described in Figure 2I. (E) Cell-based ubiquitylation analysis was performed in HEK293T cells cotransfected with the indicated expression vectors for $48 \mathrm{~h}$. $(F)$ The cellular localization of Hrd1 and Nrf2 was detected by live-cell imaging, with representative images shown in the left panel. NIH3T3 cells were cotransfected with CFP-Hrd1 and RFP-Nrf2 for $24 \mathrm{~h}$. Inversed colocalization of CFP-Hrd1 and RFP-Nrf2 is indicated with a white arrow. A cell that contains more than two inversed colocalization dots was considered as "positive." At least 50 cells from either the control or the MG132-treated group were counted to get the percentage of cells showing an inverse correlation in their signal intensities between Hrd1 and Nrf2.

correlated with higher Hrd1 and lower HO-1 in $X B P 1^{+/+}$ cells compared with $X B P 1^{-1-}$ cells (Fig. 4E).

\section{Hrd1 and Nrf2 interact directly}

Immunoprecipitation analyses demonstrated that exogenously and endogenously expressed Hrd1 and Nrf2 coexisted in precipitated complexes (Fig. 5A,B). To map the Hrd1-interacting domains in Nrf2, several deletion proteins purified from bacteria were used (Fig. 5C). Deletion of either Neh4 or Neh5 diminished the interaction, while deletion of both (Neh4-5) completely abolished the interaction (Fig. 5D), indicating a direct interaction between Hrdl and the Neh4-5 domains of Nrf2. This was further confirmed in a cell-based assay by the fact that Nrf2$\Delta$ Neh4 or Nrf2- $\Delta$ Neh5 immunoprecipitated Flag-Hrd1 less efficiently compared with wild-type Nrf2 (Nrf2-WT), and Nrf2- $\Delta$ Neh4-5 did not immunoprecipitate Flag-Hrd1 at all
(Fig. 5E). Moreover, overexpression of Hrd1 reduced Nrf2-WT but was unable to reduce the protein level of Nrf2- $\Delta$ Neh4-5 (Fig. 5 F), which supports the notion that Neh4-5 domains interact with Hrdl and that this interaction is important for down-regulation of Nrf2 by Hrd1.

To map the domain within Hrd1 that interacts with Nrf2, we performed an in vitro binding assay using Histagged Nrf2 purified from bacteria and Flag-tagged Hrd1 proteins immunoprecipitated from HEK293T cells (Fig. 5G). As expected, His-Nrf2 was immunoprecipitated by Flag-Hrd1, whereas the interaction of His-Nrf2 with FlagHrd1-N or Flag-Hrd1-N-RING was completely lost when the C-terminal domain (amino acids 337-617) of Hrd1 was deleted (Fig. 5G). The C-terminal domain of Hrd1 was found to be sufficient to immunoprecipitate Nrf2 (Fig. 5G). These results suggest a direct interaction between 


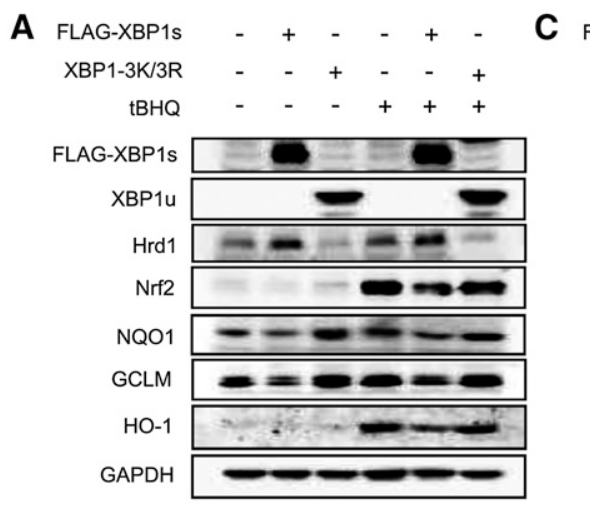

B

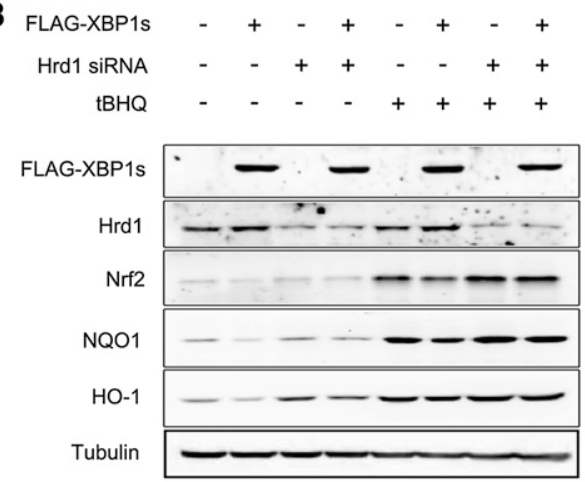

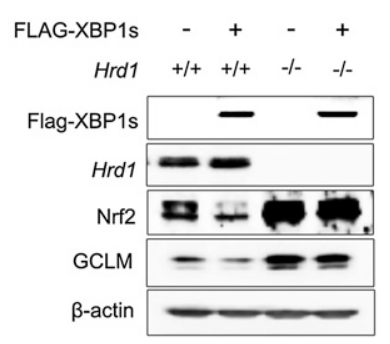

D $\mathrm{tBHQ}_{\mathrm{H}}-\mathrm{T}_{\mathrm{-}}+$

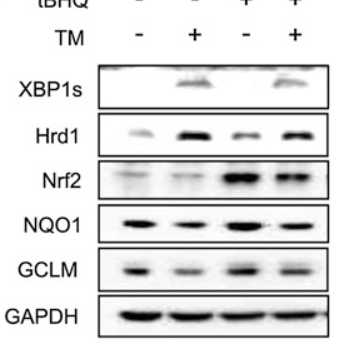

E

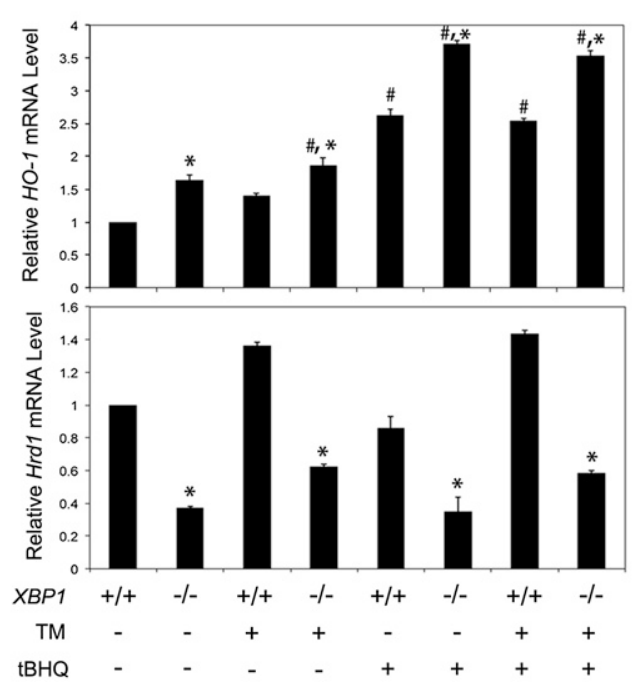

Figure 4. XBP1s down-regulates Nrf2 through Hrd1. (A) The protein levels of the indicated proteins in HEK293T cells transfected with vector, Flag-XBP1s, or XBP1-3K/3R and treated with tBHQ for $16 \mathrm{~h} .(B)$ The protein levels of the indicated proteins in HEK293T cells cotransfected with Hrd1-siRNA along with an empty vector or Flag-XBP1s. Cells were then treated with tBHQ for $16 \mathrm{~h}$. $(C)$ The protein levels of the indicated proteins in $\mathrm{Hrd1}^{+/+}$and $\mathrm{Hrd1}^{-1-}$ MEF cells transfected with an empty vector or Flag-XBP1s for $24 \mathrm{~h}$. (D) The protein levels of the indicated proteins in HEK293T cells left untreated or treated with transmembrane (TM), tBHQ, or both for $16 \mathrm{~h}$. (E) The mRNA levels of $\mathrm{HO}-1$ and $\mathrm{Hrd1}$ in $\mathrm{XBP}^{+/+}$and $\mathrm{XBP} 1^{-/-}$MEF cells treated with $\mathrm{TM}$, tBHQ, or both for $16 \mathrm{~h}$. Data are shown as mean $\pm \mathrm{SD}(n=3$ independent experiments).

the C-terminal domain of Hrd1 and the Neh4-5 domains of Nrf2, which is consistent with the notion that Nrf2 is a cytosolic protein and interacts with the cytosolic C-terminal domain of Hrd1.

\section{Hrd1 is a novel E3 ubiquitin ligase of Nrf2}

The RING domain of Hrdl contains a cysteine critical for its ubiquitin ligase activity. To identify this critical cysteine residue in the RING domain, six Hrdl mutant proteins in which each cysteine was replaced with serine were constructed (Fig. 6A). Hrd1-C291S was found to be critical for its function because overexpression of wildtype Hrd1 (Hrd1-WT), not Hrd1-C291S, reduced Nrf2 and HO-1 levels (Fig. 6B). Consistently, only Hrd1-WT, not Hrd1-C291S, was able to enhance ubiquitylation of Nrf2 both in a cell-based assay (Fig. 6C) and in vitro (Fig. 6D). Overexpression of Hrd1-WT accelerated degradation of Nrf2 (from $38.7 \mathrm{~min}$ to $17.7 \mathrm{~min}$ ), while Hrd1-C291S had no effect on Nrf2 protein decay (38.7 min to $40.2 \mathrm{~min}$ ) (Fig. 6E). Collectively, these results demonstrate that Cys291 within the RING domain of Hrd1 is indispensable for its ubiquitin ligase activity.
To demonstrate that Hrd1 functions independently of Keap1 or $\beta$-TrCP, previously defined E3 ligases that control Nrf2 protein stability (Kobayashi et al. 2004; Zhang et al. 2004; Rada et al. 2011, 2012; Chowdhry et al. 2013), we performed several additional experiments. Overexpression of XBP1s or Hrd1 reduced Nrf2 levels in Keap $1^{-1-}$ cells (Fig. 6F). In addition, ectopically expressed Hrd1 decreased not only Nrf2-WT but also Nrf2-ETGE/ AAAA and Nrf2-DLG/AAA mutant proteins that were previously proven to lose interaction with Keap1, preventing degradation by Keapl-mediated ubiquitylation and subsequent proteasomal degradation (Fig. 6G; McMahon et al. 2006; Tong et al. 2006). These results suggest that Hrd1-mediated Nrf2 degradation is Keap1-independent. Next, to prove that Hrd1-mediated Nrf2 degradation is also independent of $\beta$-TrCP, we made two additional constructs, Nrf2-ETGE+S2 and Nrf2-ETGE-DLG+S2, that were confirmed to be resistant to both Keap1- and $\beta$-TrCPmediated degradation (data not shown). However, Hrd1 was still able to reduce the protein level of these two mutants (Fig. $6 \mathrm{H}$ ), indicating that the ligase activity of Hrd1 in ubiquitylating Nrf2 is not associated with Keap1 or $\beta$-TrCP. Next, we tested whether the seven lysines 
Wu et al.
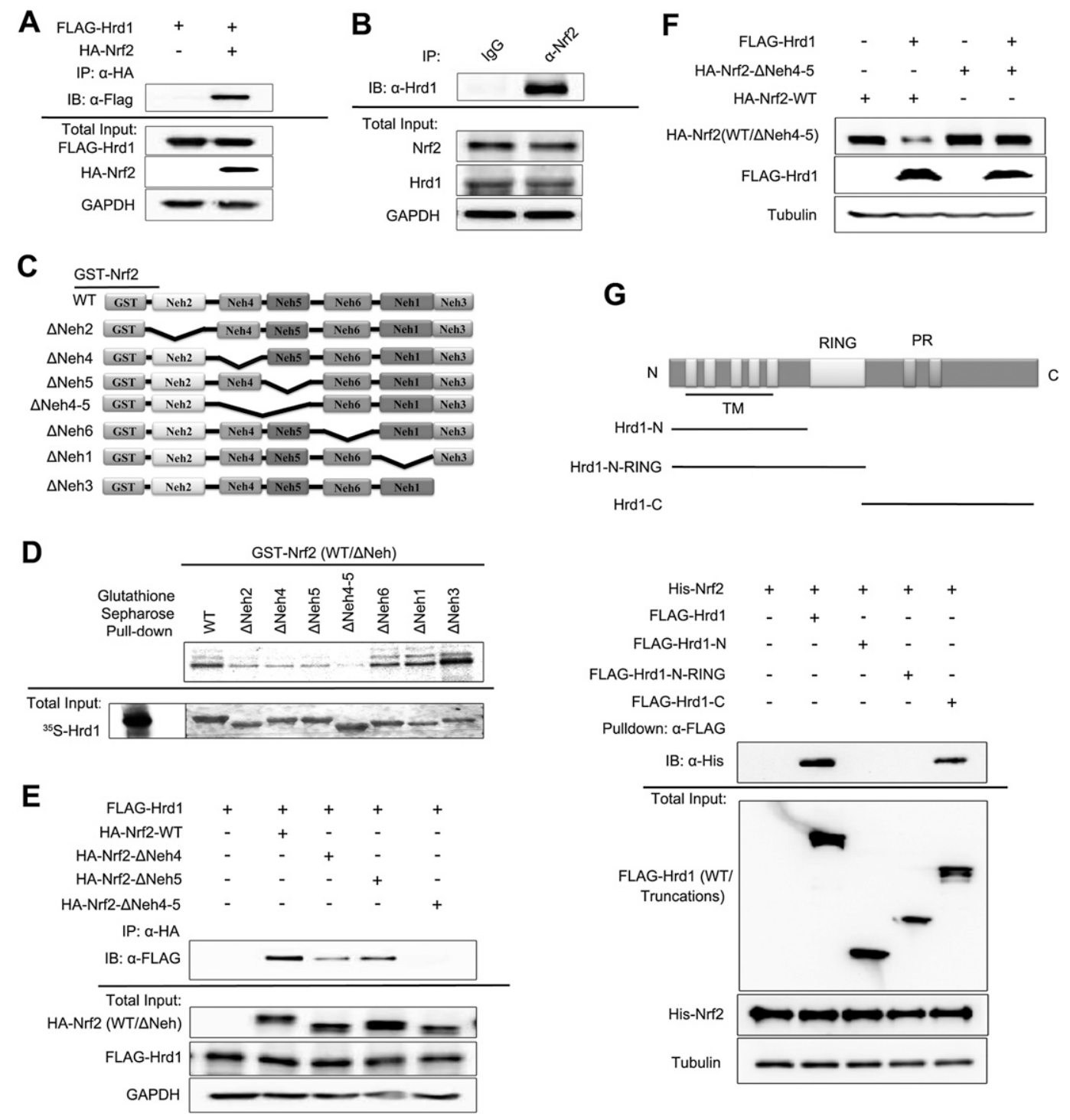

Figure 5. Hrd1 and Nrf2 interact directly. (A) Immunoprecipitation analysis was performed using cell lysates from HEK293T cells cotransfected with Flag-Hrd1 and hemagglutinin (HA)-tagged Nrf2 (HA-Nrf2). (B) Immunoprecipitation analysis was performed using cell lysates from HEK293T cells, immunoprecipitated by normal rabbit IgG or anti-Nrf2 antibody. $(C)$ Schematic illustration of glutathione S-transferase (GST)-tagged Nrf2-WT and its deletion mutants used for interaction domain mapping. $(D)$ Sepharose affinity chromatography analysis of the interaction between Nrf2 and Hrd1. $\left.{ }^{35} \mathrm{~S}\right]-\mathrm{Hrd} 1$-WT was generated by in vitro transcription and translation. GST-tagged Nrf2-WT and its indicated deletion mutants were expressed and purified from Escherichia coli cells. Equal amounts of Nrf2 proteins were used for each pull-down assay. $(E)$ Immunoprecipitation analysis was performed using cell lysates of HEK293T cells cotransfected with Flag-Hrd1 and either HA-Nrf2, HA-Nrf2- $\Delta$ Neh4, HA-Nrf2- $\Delta$ Neh5, or HA-Nrf2- $\Delta$ Neh4-5. $(F)$ Immunoblot analysis was performed with cell lysates from HEK293T cells cotransfected with Flag-Hrd1 and either Nrf2-WT or Nrf2- $\Delta$ Neh4-5 for 24 h. (G) Immunoprecipitation of Nrf2 by Flag-Hrd1 and its mutants. HEK293T cells were transfected with Flag-Hrd1 and the indicated truncation mutants. Hrd1 proteins were first immunoprecipitated using Flag-M2 beads and then incubated with Histagged Nrf2 that was expressed and purified from E. coli cells. Equal amounts of Hrd1 proteins were used for each experiment.

within the Neh2 domain of Nrf2 are also required for Hrd1-mediated ubiquitylation. The same seven lysines in Nrf2 that are required for Keap1-dependent ubiquitylation of Nrf2 (Zhang et al. 2004) were also critical for Hrd1mediated Nrf2 ubiquitylation and degradation, since Nrf2-K7/R7 was not affected by overexpression of Hrd1 (Fig. 6I). In addition, Hrd1-mediated ubiquitylation and degradation of Nrf2 occurs in the cytosol, since Hrd1 reduced only the protein levels of Nrf2-WT and the cytoplasmic-only version of Nrf2 (Nrf2-NLS2) in which the nuclear localization signal RKRK was mutated to AAAA, but Hrd1 had no effect on Nrf2-NES1 and Nrf2NES2, which were forced to localize in the nucleus due to mutations made in their nuclear export signals (Fig. 6J; Sun et al. 2007). Taken together, these results clearly demonstrate that Hrd1, an ER-associated E3 ubiquitin 
A

RING domain of Hrd1

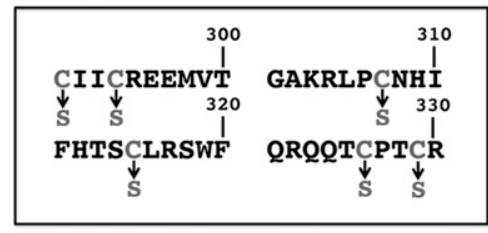

B

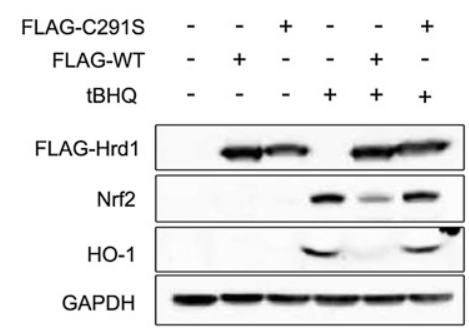

C
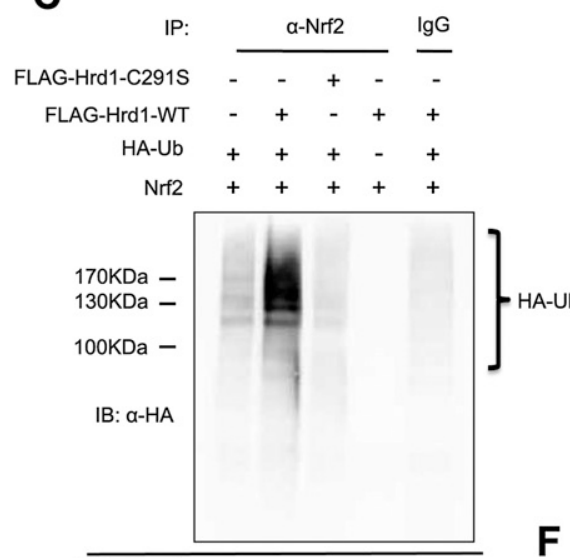

Total Input:

Nrf2

FLAG-Hrd1

GAPDH

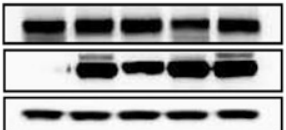

$\mathbf{F}$
E

$\begin{array}{rrrrrr}\text { E1 } & - & + & + & + & + \\ \text { E2 } & + & - & + & + & + \\ \text { Ub } & + & + & - & + & + \\ \text { FLAG-WT } & + & + & + & + & - \\ \text { FLAG-C291S } & - & - & - & - & + \\ \text { HA-Nr2 } & + & + & + & + & + \\ \text { ATP } & + & + & + & + & +\end{array}$

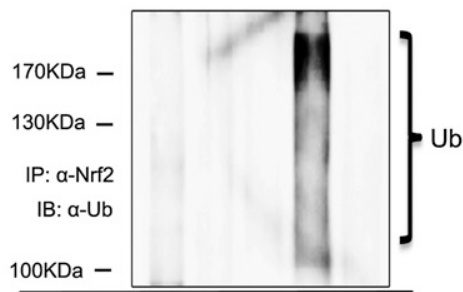

Total Input:

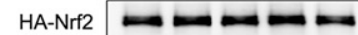

FLAG-Hrd1

GAPDH

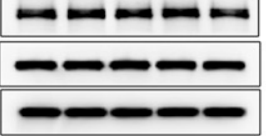

FLAG-C291S - $-\quad-\quad-\quad-\quad-+++$

FLAG-WT - - - $++++\cdots$

$\mathrm{CHX} \quad 0 \quad 102040 \quad 0 \quad 102040 \quad 0 \quad 102040$

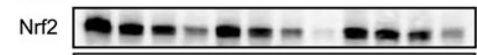

FLAG

Tubulin
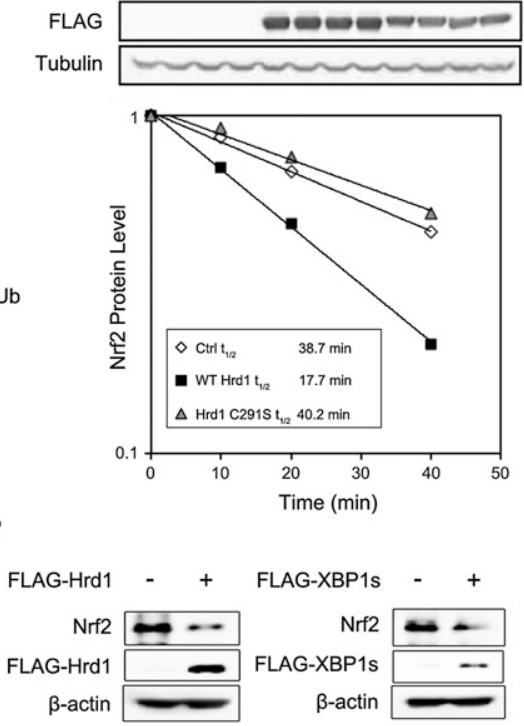

G

FLAG-Hrd1 - +-+-+

HA-Nrf2 (DLG/AAA) - $\quad-\quad-\quad-\quad+\quad+$

HA-Nrf2 (ETGE/AAAA) - $-++\quad-$

$\mathrm{HA}-\mathrm{Nrf2}++-\quad-\quad-$

HA-Nrf2 $=-m$

FLAG-Hrd1

Tubulin

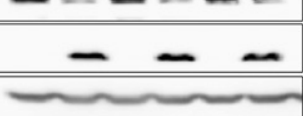

H

FLAG-Hrd1 - + - + - +

$\mathrm{HA}-\mathrm{Nrf2}++--\quad-$

HA-Nrf2-ETGE+S2 - -++-

HA-Nrf2-ETGE-DLG+S2 - $\quad-\quad-\quad-\quad+\quad+$

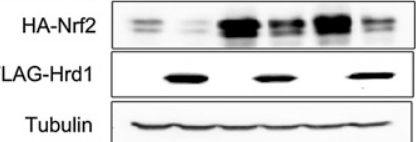

FLAG-Hrd1

Tubulin

I
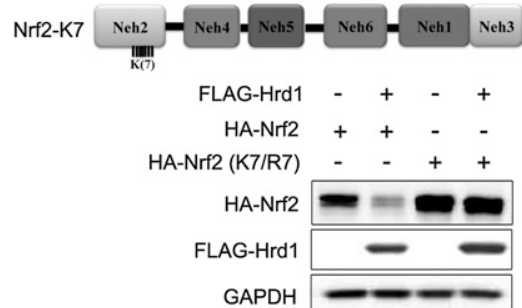

J

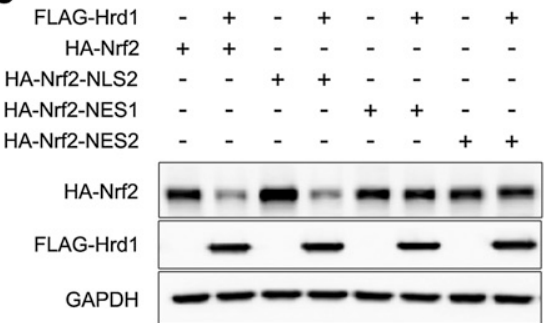

Figure 6. Hrd1 is a novel E3 ubiquitin ligase of Nrf2. (A) Schematic illustration of the amino acid sequence of the RING domain of Hrd1. Conserved cysteine residues that are mutated to serines are labeled with arrows. $(B)$ Immunoblot analysis of cell lysates from HEK293T cells transfected with an empty vector, Flag-Hrd1, or Flag-C291S. Cells were untreated or treated with tBHQ for 16 h. (C) Cell-based ubiquitylation analysis was performed in HEK293T cells cotransfected with Nrf2, Flag-Hrd1, or Flag-C291S mutant and HAubiquitin for $48 \mathrm{~h}$. $(D)$ In vitro ubiquitylation of Nrf2 in the presence of Flag-Hrd1 and Flag-C291S was measured. HA-Nrf2-containing complexes were immunoprecipitated using HA beads from HEK293T cells transfected with Nrf2 and either Flag-Hrd1-WT or FlagHrd1-C291S. HA bead-bound proteins were incubated with purified E1, E2-UbcH5c, ubiquitin, and ATP. Following denaturation by boiling, Nrf2 was immunoprecipitated with anti-Nrf2 antibodies, and ubiquitylation of Nrf2 was detected by immunoblot analysis with an anti-ubiquitin antibody. (E) The Nrf2 protein half-life in HEK293T cells transfected with either an empty vector, Flag-Hrd1, or Flag-C291S was measured as described above. $(F)$ Immunoblot analysis of Nrf2 in Keap1 $1^{-/-}$MEF cells transfected with an empty vector, Flag-Hrd1, or Flag-XBP1s for $24 \mathrm{~h}$. $(G)$ Immunoblot analysis of the indicated proteins. HEK293T cells were cotransfected with Flag-Hrd1 and either Nrf2-WT, Nrf2-ETGE/AAAA, or Nrf2-DLG/AAA. (H) Immunoblot analysis of the indicated proteins. HEK293T cells were cotransfected with Flag-Hrd1 and either Nrf2-WT, Nrf2-ETGE+2S, or Nrf2-ETGE-DLG+2S. (I) Immunoblot analysis of the indicated proteins. HEK293T cells were cotransfected with Flag-Hrd1 and either Nrf2-WT or Nrf2-K7/R7 for 24 h. (J) Immunoblot analysis of the indicated proteins. HEK293T cells were cotransfected with Flag-Hrd1 and either Nrf2-WT, Nrf2-NLS2, Nrf2-NES1, or Nrf2-NES2. 
Wu et al.

ligase, is a novel E3 ubiquitin ligase controlling Nrf2 though an interaction between the C-terminal domain of Hrd1 and the Neh4-5 domains of Nrf2. This Hrd1mediated ubiquitylation of Nrf2 is independent of both Keap1 and $\beta$-TrCP.

\section{Pharmacological inhibition of Hrd1 as a strategy to prevent loss of the Nrf2-mediated protective mechanism}

Our results indicate that loss of the Nrf2-mediated cellular protection through Hrd1-mediated ubiquitylation and subsequent proteasomal degradation of Nrf2 may be crucial in determining liver disease outcome. This observation argues for a novel therapeutic strategy for treating liver cirrhosis by targeting Hrd1 to preserve the Nrf2 protective response rather than using currently available Nrf2 inducers that only block Keap1-dependent ubiquitylation of Nrf2. Therefore, we tested whether Hrdl is a potential therapeutic target for preventing/ mitigating liver cirrhosis through enhancement of the Nrf2-regulated protective mechanism. Two compounds, 4U8C (IRE1 inhibitor) (Cross et al. 2012; Qiu et al. 2013) and LS-102 (Hrd1 inhibitor) (Yagishita et al. 2012), were tested for their ability to alleviate liver cirrhosis in $\mathrm{Nrf}^{+/+}$ and $\mathrm{Nrf2}^{-/-}$mice. In $\mathrm{Nrf2} 2^{+/+}$mice, $\mathrm{CCl}_{4}$ increased XBP1s and $\mathrm{Hrd} 1$ protein levels while decreasing Nrf2, NQO1, and GCLM protein levels (Fig. 7A,B). 4U8C suppressed $\mathrm{CCl}_{4}$ mediated up-regulation of XBP1s and Hrd1 and restored the protein levels of Nrf2, NQO1, and GCLM (Fig. 7A,B). LS-102 suppressed down-regulation of Nrf2 and its target genes induced by $\mathrm{CCl}_{4}$ treatment while having no effect on the protein levels of XBP1s and Hrd1, consistent with its mode of action (Fig. 7A,B; Yagishita et al. 2012). Although the expression pattern of XBP1s and Hrd1 in response to both inhibitors was similar in $\mathrm{Nrf2}^{+/+}$and Nrf2 $2^{-1-}$ mice, the expression levels of NQO1 and GCLM remained the same in the inhibitor-treated $\mathrm{Nrf}^{-/-}$ groups (Fig. 7A,B). Furthermore, neither $\mathrm{CCl}_{4}$ nor the two inhibitors affected Nrf2 or Keap1 mRNA levels (Fig.
A

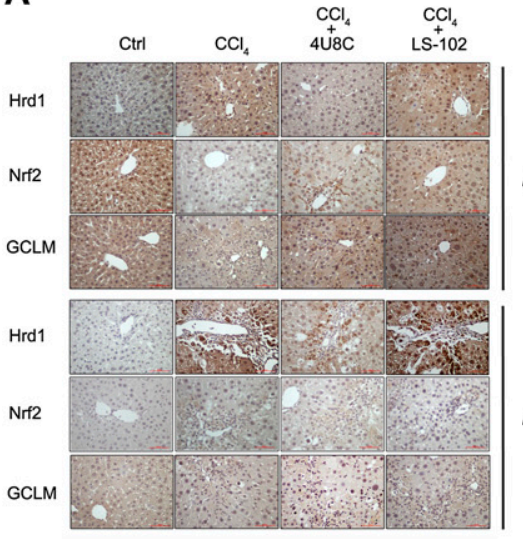

B

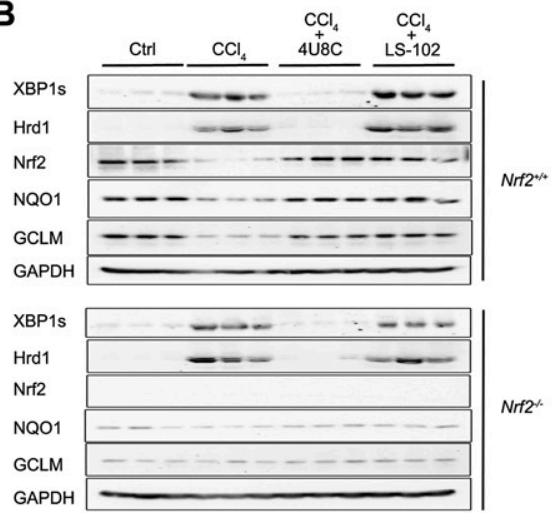

C

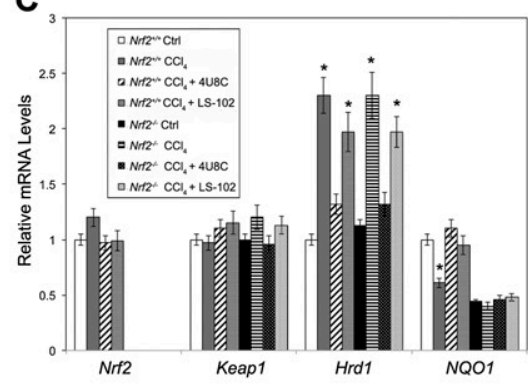

$\mathrm{NrF}^{\prime-}$

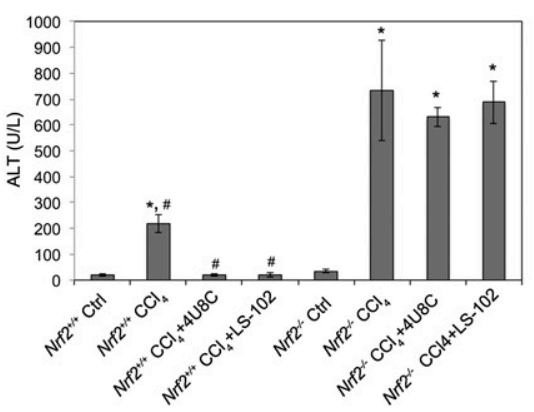

$\mathbf{E}$

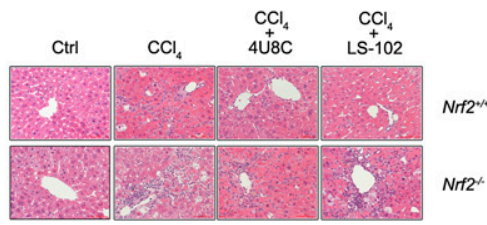

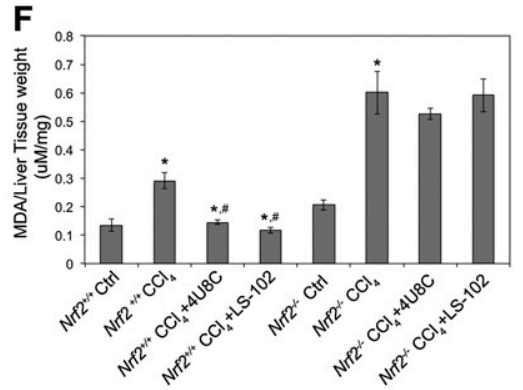

G

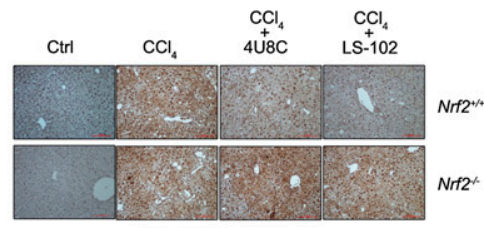

H

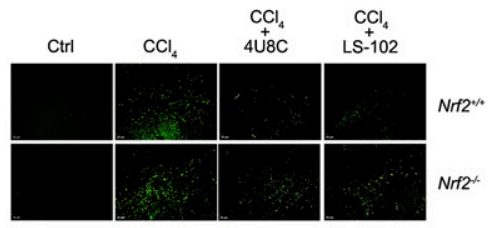

i

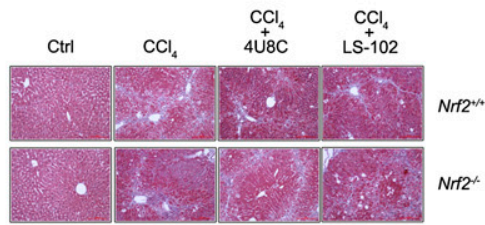

Figure 7. Pharmacological inhibition of Hrd1 as a strategy to prevent loss of the Nrf2-mediated protective mechanism. $(A-I)$ IHC staining $(A)$; the protein levels of the indicated proteins $(B)$; the mRNA levels of the indicated genes $(C)$; serum levels of alanine aminotransferase (ALT), a key index for liver function $(D)$; H\&E staining (E); malonyl dialdehyde (MDA), an indicator for lipid peroxidation $(F)$; 8-hydroxydeoxyguanosine (8-OH-dG) for oxidative DNA damage $(G)$; apoptotic cell death as indicated by TUNEL staining $(H)$; and collagen deposition measured using Masson's trichrome staining $(I)$ were conducted with liver tissues from $\mathrm{Nrf2} 2^{+/+}$and $N r f 2^{-1-}$ mice treated with vehicle control, $\mathrm{CCl}_{4}, \mathrm{CCl}_{4}$ plus $4 \mathrm{U} 8 \mathrm{C}$, and $\mathrm{CCl}_{4}$ plus LS-102. Four mice were used in each group. Treatment regimens are described in the Materials and Methods. $(B)$ For immunoblot analysis, each lane contains a tissue lysate from an individual mouse. For results expressed as bar graphs, means and SD were from four mice $(n=4)$. 
7C). 4U8C, but not LS-102, suppressed $\mathrm{CCl}_{4}$-induced upregulation of $\mathrm{Hrd} 1$ mRNA in both $\mathrm{Nrf2}^{+/+}$and $\mathrm{Nrf2}^{-{ }^{-}}$ mice (Fig. 7C). However, NQO1 mRNA was restored by drugs only in $\mathrm{Nrf2}^{+/+}$mice (Fig. 7C). Next, the effect of 4U8C and LS-102 in alleviating liver cirrhosis was tested. Both 4 U8C and LS-102 were able to suppress $\mathrm{CCl}_{4^{-}}$ induced elevation of alanine aminotransferase (ALT) in $\mathrm{Nrf2}^{+/+}$but not in $\mathrm{Nrf2}^{-/-}$mice (Fig. 7D). Hematoxylin and eosin $(\mathrm{H} \& \mathrm{E})$ staining showed that both LS-102 and 4U8C restored normal liver morphology in $\mathrm{Nrf2}^{+/+}$but not in $\mathrm{Nrf2}^{-/-}$mice, although LS-102 had the larger effect (Fig. 7E). Moreover, lipid peroxidation and oxidative DNA damage, measured as malonyl dialdehyde (MDA) and 8-hydroxydeoxyguanosine (8-OH-dG), respectively, were corrected to a level almost similar to the untreated group by LS-102 and 4U8C (Fig. 7F,G). In addition, apoptotic cell death was significantly reduced in $\mathrm{Nrf2}^{+/+}$mice but only slightly in $\mathrm{Nrf2}^{-/-}$mice (Fig. $7 \mathrm{H}$ ), and both drugs reduced collagen deposition in $\mathrm{Nrf2}^{+/+}$but not in $\mathrm{Nrf2}^{---}$mice, as revealed by trichrome staining (Fig. 7I).

\section{Discussion}

It has been well documented that boosting the Nrf2mediated cellular protective response offers protection against chronic diseases induced by accumulation of oxidatively damaged biomolecules (Kensler et al. 2007; Jaramillo and Zhang 2013). Therefore, identifying and developing small-molecule Nrf2 activators for disease prevention and intervention have been areas of intensive research. Interestingly, the basal Nrf2 levels were found to be low in aged organisms and certain pathological conditions (Sykiotis and Bohmann 2010; Kurzawski et al. 2012). The detailed mechanisms underlying age- and disease-related down-regulation of Nrf2 are unclear, but this knowledge is critical for developing a rational strategy to prevent loss of this major cellular protective response. Keap1 has been regarded as the primary E3 ubiquitin ligase controlling the protein level of Nrf2 and its downstream response (Kobayashi et al. 2004; Zhang et al. 2004). Accordingly, all Nrf2 activators known to date function by targeting Keap1 (Ma and He 2012; Magesh et al. 2012).

In this study, we discovered that the E3 ubiquitin ligase that compromised the Nrf2 response in cirrhotic liver is Hrd1 and not Keap1 or $\beta$-TrCP. Hrd1 has an essential developmental role, and aberrant expression of $\mathrm{Hrd} 1$ has been associated with a number of chronic diseases (Amano et al. 2003; Yagishita et al. 2005; Hasegawa et al. 2010). For instance, it was shown to be up-regulated in rheumatoid synovial cells, and overexpression of $\mathrm{Hrd} 1$ resulted in spontaneous arthropathy, whereas $\mathrm{Hrd1}^{+/-}$ mice were more resistant to collagen-induced arthritis (Amano et al. 2003). Recently, Hrdl was also found to be up-regulated in $\mathrm{CCl}_{4}$-induced fibrotic livers, and $\mathrm{Hrd1}^{+/-}$ mice had fewer activated hepatic stellate cells, less collagen accumulation, and less hepatic injury compared with $\mathrm{Hrd1}^{+/+}$mice (Hasegawa et al. 2010). The molecular mechanisms underlying the pathological roles of Hrdl in these diseases are presumably derived from its function as an E3 ubiquitin ligase. Initially, it was thought that Hrd1 only regulated the turnover of proteins in the ERAD system, since Hrdl resides in the ER membrane. More recently, however, Hrd1 substrates that control specific signaling pathways have been identified, including p53, Nrf1, Rer1, and IRE1 (Yamasaki et al. 2007; Gao et al. 2008; Steffen et al. 2010; Tanabe et al. 2012). In this study, we show that Nrf2 is a bona fide substrate of Hrd1. This activity is mediated through the direct binding between the Neh4-5 domains of Nrf2 and the cytosolic C-terminal domain of Hrd1. The inverse correlation in the expression of Nrf2 and Hrd1 was observed in both human and mouse cirrhotic livers. Furthermore, silencing of Hrdl in the livers of conditional knockout mice markedly enhanced the expression of Nrf2 and its target genes. All of these observations support the functional importance of Hrd1mediated control of Nrf2 in disease settings.

In support of our finding, negative regulation of ER stress on Nrf2 was observed in an in vivo study comparing the gene expression profile in the small intestine and liver in response to tunicamycin treatment. Many phase II detoxifying genes, including glutathione S-transferase (GST) isoforms and GCLM, were found to be downregulated in an Nrf2-dependent manner (Nair et al. 2007). Combined with the results from our study, it is likely that the observed down-regulation of the Nrf2mediated response in the early study was due to the upregulation of Hrd1 by tunicamycin. Inconsistent with our data, a recent study comparing gene expression profiles from human liver tissues from normal, steatosis, alcohol cirrhosis, and diabetic cirrhosis showed increased Nrf2 levels and increased downstream genes in alcoholic and diabetic cirrhotic livers compared with normal nonsteatotic livers (More et al. 2013). The alcoholic cirrhotic liver tissues used in this study are from the same repository as ours. Therefore, it is unclear why the opposite outcomes regarding Nrf2 activation were obtained. However, the observed changes in the expression of Nrf2 and NQO1 in both studies are marginal, which may be due to the heterogeneity of human samples. Crucially, the experiments carried out using a mouse model clearly show the negative regulation between Hrd1 and Nrf2 or Nrf2 target genes (Fig. 1, cf. A-C and D-F or G-I). Furthermore, while our data explain pathological conditions when the overly activated IRE1-XBP1 arm of ER stress suppressed the Nrf2 protective mechanism, it is unclear what role, if any, the negative regulation of Nrf2 by Hrd1 may have under physiological conditions. We believe that Cul3-Keap1-Rbxl is the primary E3 ligase that targets Nrf2 for ubiquitylation and degradation under physiological conditions. Therefore, it is reasonable to speculate from an evolutionary point of view that Hrd1-mediated regulation of Nrf2 is a way to get rid of cells that have activated the IRE1-XBP1 ER stress pathway, and cellular homeostasis can no longer be achieved.

As illustrated in Supplemental Table 1, Keap1-Cul3Rbx1 was the first Nrf2 E3 ubiquitin ligase identified (Kobayashi et al. 2004; Zhang et al. 2004). Structural studies have demonstrated that a Keap1 dimer binds Nrf2. Each Kelch domain in Keap1 interacts with either a DLG or an ETGE motif in the Neh2 domain of Nrf2 (McMahon et al. 2006; Tong et al. 2006). The seven 
lysines between the DLG motif and the ETGE motif of Nrf2 were required for receiving a polyubiquitin chain (Zhang et al. 2004). Presently, all small chemical Nrf2 activators or endogenous proteins identified disrupt the DLG-Kelch interaction to suppress Nrf2 ubiquitylation, resulting in stabilization of Nrf2 and activation of the pathway (Magesh et al. 2012; Jaramillo and Zhang 2013). Recently, $\beta$-TrCP-Skp1-Cul1-Rbx1 was also identified as an E3 ubiquitin ligase for Nrf2 (Rada et al. 2011, 2012; Chowdhry et al. 2013). Two motifs, DSGIS and DSAPGS, in the Neh6 domains of Nrf2 were determined to interact with $\beta$-TrCP. Phosphorylation of the serine residues in DSGIS resulted in recruitment of Nrf2 by $\beta$-TrCP into the E3 ligase complex, with subsequent ubiquitylation of Nrf2 (Rada et al. 2011, 2012; Chowdhry et al. 2013). However, phosphorylation of DSAPGS is not required (Chowdhry et al. 2013). In the present study, we identified Hrd1 as another E3 ubiquitin ligase that down-regulates Nrf2 during the course of liver cirrhosis. Until now, Keap1, $\beta$-TrCP, and Hrd1 are three E3 ubiquitin ligases of Nrf2 that have been discovered (Supplemental Table 1). It is also worth mentioning that only $\beta$ - TrCP and $\mathrm{Hrd} 1$, but not Keap1, are the E3 ubiquitin ligases for Nrf1, another member of the CNC family, even though Nrfl also contains Keap1-binding DLG and ETGE motifs (Supplemental Table 1; Zhang et al. 2006; Steffen et al. 2010; Tsuchiya et al. 2011). Understanding how Nrf2 is controlled in distinct pathophysiological conditions and developing Nrf2 modulators to inactivate the appropriate E3 ligases are crucial for targeted disease prevention and intervention. To illustrate, we demonstrated the importance of targeting Hrdl, instead of Keap1, to preserve the Nrf2 defense system, which suppresses the progression of liver cirrhosis. In cirrhotic livers, high levels of ROS inactivate Keap1, which should lead to high Nrf2 levels. However, we observed low Nrf2 levels in cirrhotic liver tissues compared with normal liver tissues. Hrd1 turned out to be the primary E3 ubiquitin ligase controlling the Nrf2 protective response in cirrhotic livers. We showed that inhibition of Hrdl directly with LS102 or indirectly through IRE1 inhibition with 4U8C was able to restore the Nrf2 response, reduce oxidative damage, and alleviate liver injury and cirrhosis.

In summary, we discovered cross-talk between two major cellular stress response pathways: the IRE1-XBP1Hrd1 arm of the ER stress response pathway and the cytoprotective Nrf2-mediated oxidative stress response pathway. These two pathways converge through Hrdlmediated Nrf2 ubiquitylation. We demonstrated that Hrd1-mediated suppression of the Nrf2-dependent cytoprotective pathway plays a crucial role in the pathogenesis of liver cirrhosis. Finally, the therapeutic importance of our findings was demonstrated by showing that pharmacological inhibition of Hrd1 alleviated liver injury and cirrhosis in an Nrf2-dependent manner.

\section{Materials and methods}

\section{Liver samples and preparations}

Normal human liver tissues and cirrhotic liver tissues from endstage alcoholic cirrhosis patients were obtained through the
Liver Tissue Cell Distribution System, Minneapolis, Minnesota, which was funded by National Institutes of Health contract number HHSN276201200017C.

\section{Generation of $\mathrm{Hrd1}^{\mathrm{flf}}$ mice}

The Hrd1 gene contains 16 exons; we floxed exons 8-11, which encode a large region of the Hrdl protein from its fifth transmembrane domain to the proline-rich sequence (Fig. 4G). To exclude the potential effects of the neomycin selection cassette on Hrd1 expression, this cassette was flanked by two flippase recognition target (FRT) sites, which can be deleted by FLP recombinase. This targeting vector was transfected into an embryonic stem cell line generated from C57/BL6 mice. The neomycin selection marker was screened by PCR. Seven clones were obtained and confirmed by Southern blotting. Blastocyst injections resulted in several chimeric mice with the capacity for germline transmission. Breeding of heterozygous mice yielded $\mathrm{Hrd1}^{+/+}, \mathrm{Hrd}^{+/ \mathrm{f}}$, and $\mathrm{Hrd}^{\mathrm{f} / \mathrm{f}}$ mice with the expected Mendelian ratios. No obvious phenotypic abnormalities were observed in all genotypes.

\section{Animal treatment}

For the liver cirrhosis model, male $\mathrm{Nrf}^{+/+}$and $\mathrm{Nrf2}^{-/-}$mice at the age of 6 wk were IP-injected with $1 \mathrm{~mL} / \mathrm{kg} 50 \%(\mathrm{v} / \mathrm{v}) \mathrm{CCl}_{4}$ or olive oil three times a week for 4 wk. For cotreatment groups, animals received IP injection of $5 \mathrm{mg} / \mathrm{kg} 4 \mathrm{U} 8 \mathrm{C}$ and $1.3 \mathrm{mg} / \mathrm{kg}$ LS102 daily. Animals were sacrificed $24 \mathrm{~h}$ after the last injection of $\mathrm{CCl}_{4}$, and liver tissues and serum were collected for analysis.

\section{H\&E, IHC analysis, and Masson's trichrome staining}

$\mathrm{H} \& \mathrm{E}, \mathrm{IHC}$, and Masson's trichrome staining analyses were performed as described previously (Jiang et al. 2009; Zheng et al. 2011a). Briefly, paraffin-embedded liver tissues were cut into 4- to 5- $\mu \mathrm{m}$ sections and stained with $\mathrm{H} \& \mathrm{E}$ or the indicated antibodies. The trichrome stain (Masson) kit was purchased from Sigma, and the procedure was carried out according to the manufacturer's instructions.

\section{Construction of recombinant DNA molecules}

Plasmids expressing Flag-tagged XBP1s and XBP1-3K/3R were generous gifts from Dr. Laurie H. Glimcher (Harvard School of Public Health). Flag-tagged wild-type and truncated forms of Hrd1 were PCR-amplified using cDNAs reverse-transcribed from mRNAs of HEK293T cells and subcloned into the pCMVFlag-5a vector using EcoRI/BamHI restriction sites. The Hrd1C291S mutation was generated by site-directed mutagenesis using the PCR and DpnI method. Hemagglutinin (HA)-tagged, His-tagged, and GST fusion proteins of Nrf2-WT and Nrf2 domain deletion mutants have been previously described (Sun et al. 2009). To construct the fluorescent-tagged proteins for live-cell imaging, Hrd1 and Nrf2 were cloned into CFP and RFP vectors, respectively. The following restriction enzyme cutting sites were used to generate the fluorescently tagged proteins: Xhol/BamHI (Nrf2-RFP) and Hind III/BamHI (Hrd1CFP). Plasmids expressing wild-type HA-Nrf2 proteins have been previously described (Zhang and Hannink 2003). Plasmids for the Nrf2 domain deletion mutants were originally generated by PCR and three-way ligation into the pCMV-HA vector (Clontech) using SalI/KpnI and KpnI/NotI cutting sites. The primers used for Nrf2 domain deletion mutants are listed in Table 1. 
Table 1. Primers used for Nrf2 domain deletion mutants

\begin{tabular}{|c|c|}
\hline Wild type & 5'-ACACACGGGTCGACGCTCATCATGATGGACTTGGAGCTGCCGCCG-3' \\
\hline & 5'-GGTCAAATCCGCGGCCGCCTAGTTTTTCTTAACATCTGGCTT-3' \\
\hline$\Delta \mathrm{Neh} 2(\Delta \mathrm{AA} 1-86)$ & 5'-ACACACGGGTCGACGCTCATCATGATGGACTTGGAGCTGCCGCCG-3' \\
\hline & 5'-GGTGAATTTCTCGGTACCCAGCCAGCCCAG-3' \\
\hline & 5'-GGTCAAATCCGCGGCCGCCTAGTTTTTCTTAACATCTGGCTT-3' \\
\hline$\Delta$ Neh4 ( $\Delta$ AA112-134) & 5'-ACACACGGGTCGACGCTCATCATGATGGACTTGGAGCTGCCGCCG-3' \\
\hline & 5'-CATCAAAGTACAAGGTACCTGATTTGGGAAT-3' \\
\hline & 5'-GTTTGTAGATGACGGTACCGTTTCTTCGGCT-3' \\
\hline & 5'-GGTCAAATCCGCGGCCGCCTAGTTTTTCTTAACATCTGGCTT-3' \\
\hline$\Delta$ Neh5 ( $\Delta$ AA182-200) & 5'-ACACACGGGTCGACGCTCATCATGATGGACTTGGAGCTGCCGCCG-3' \\
\hline & 5'-CAAACTTGCTCAATGGTACCTTGCATACCGTC-3' \\
\hline & 5'-CCTGAGTTACAGGGTACCAATATTGAAAATG-3' \\
\hline & 5'-GGTCAAATCCGCGGCCGCCTAGTTTTTCTTAACATCTGGCTT-3' \\
\hline$\Delta$ Neh4-5 ( $\Delta$ AA112-200) & 5'-ACACACGGGTCGACGCTCATCATGATGGACTTGGAGCTGCCGCCG-3' \\
\hline & 5'-CATCAAAGTACAAGGTACCTGATTTGGGAAT-3' \\
\hline & 5'-CCTGAGTTACAGGGTACCAATATTGAAAATG-3' \\
\hline & 5'-GGTCAAATCCGCGGCCGCCTAGTTTTTCTTAACATCTGGCTT-3' \\
\hline$\Delta$ Neh6 $(\Delta$ AA336-386) & 5'-ACACACGGGTCGACGCTCATCATGATGGACTTGGAGCTGCCGCCG-3' \\
\hline & 5'-ATCATTGAATTCGGTACCGCTTTCAGGGTG-3' \\
\hline & 5'-GATAGTGCCGGTACCAGTGTCAAACAG-3' \\
\hline & 5'-GGTCAAATCCGCGGCCGCCTAGTTTTTCTTAACATCTGGCTT-3' \\
\hline$\Delta$ Neh1 $(\Delta$ AA434-561) & 5'-ACACACGGGTCGACGCTCATCATGATGGACTTGGAGCTGCCGCCG-3' \\
\hline & 5'-GGTTTTCCGATGGGTACCACTTACAGGCAA-3' \\
\hline & 5'-CAACTCAGCACCGGTACCCTCGAAGTTTTC-3' \\
\hline & 5'-GGTCAAATCCGCGGCCGCCTAGTTTTTCTTAACATCTGGCTT-3' \\
\hline$\Delta \mathrm{Neh} 3(\Delta \mathrm{AA} 561-604)$ & 5'-ACACACGGGTCGACGCTCATCATGATGGACTTGGAGCTGCCGCCG-3' \\
\hline & 5'-CATCACGTAGCATGGCGGCCGCTTAGAGATAAAGGTG-3' \\
\hline & 5'-GGTCAAATCCGCGGCCGCCTAGTTTTTCTTAACATCTGGCTT-3' \\
\hline
\end{tabular}

These plasmids were then used as templates for subcloning the GST-Nrf2 by PCR and ligation into the pGEX-5X-3 vector using BamHI and XhoI cutting sites.

\section{Cell culture, transfection, and RNAi}

HEK293T and MDA-MB-231 cells were purchased from American Type Culture Collection (ATCC). $X B P 1^{+/+}$and $X B P 1^{-/-} \mathrm{MEF}$ cells were a generous gift from Dr. Laurie H. Glimcher. $\mathrm{Hrd1} 1^{+/+}$ and $\mathrm{Hrd1}^{-1-}$ MEF cells were generated by our team (in the laboratory of T.N.). HEK293T cells were maintained in minimum essential medium Eagle's medium (MEM) (Cellgro) in the presence of $10 \%$ fetal bovine serum (FBS), $1 \%$ L-glutamine (Life Technologies), $1.0 \mathrm{mM}$ sodium pyruvate, $0.1 \mathrm{mM}$ nonessential amino acids (Hyclone), and $0.1 \%$ gentamycin (Life Technologies). MDA-MB-231 cells were maintained in MEM (Cellgro) in the presence of $10 \%$ FBS, $1 \%$ L-glutamine (Life Technologies), $6 \mathrm{ng} / \mathrm{mL}$ insulin (Sigma), and 0.1 mM HEPES (Life Technologies). All MEF cell lines were maintained in Dulbecco's modified Eagle's medium (DMEM) in the presence of $10 \%-20 \%$ FBS and $0.1 \%$ gentamycin. All cells were incubated at $37^{\circ} \mathrm{C}$ in a humidified incubator containing $5 \% \mathrm{CO}_{2}$. All cell culture dishes used for HEK293T cells were coated with $0.1 \mathrm{mg} / \mathrm{mL}$ poly-D-lysine (Sigma). Transfections of plasmid DNA were performed with Lipofectamine Plus reagent (Invitrogen) according to the manufacturer's instructions. siRNA against Hrdl and scrambled control siRNA were purchased from Thermo Scientifics. The four Hrd1-siRNAs (used as a mixture) were 5'-CAACAAGGCU GUGUACAUG, 5'-UGUCUGGCCUUCACCGUUU-3', 5'-GG AGAUGCCUGAGGAUGGA-3', and 5'-CCAAGAGACUGCC CUGCAA-3' (Thermo Scientific catalog nos. siGENOME SMARTpool siRNA D-007090-01, D-007090-02, D-007090-03, and D-007090-04). Transfection of siRNA was performed with Lipofectamine 2000 (Invitrogen) according to the manufacturer's instructions. In general, concentrations of $20 \mathrm{pmol}$ and $40 \mathrm{pmol}$ or siRNA gave the best silencing results and thus were used in this study.

\section{Antibodies, immunoprecipitation, and immunoblot analysis}

Rabbit anti-Nrf2 (Santa Cruz Biotechnology), anti-Hrd1 (Santa Cruz Biotechnology), anti-HO-1 (Santa Cruz Biotechnology); mouse anti-tubulin (Santa Cruz Biotechnology), anti-GAPDH (glyceraldehyde-3-phosphate dehydrogenase; Santa Cruz Biotechnology), anti-NQO1 (Santa Cruz Biotechnology), anti-8oxo-dG (Trevigen), anti-His epitope (Santa Cruz Biotechnology), anti-HA epitope (Covance), and mouse anti-Flag (Sigma) were purchased from commercial sources. To detect protein expression in total cell lysates, cells were lysed in sample buffer (50 $\mathrm{mM}$ Tris- $\mathrm{HCl}$ at $\mathrm{pH} 6.8,2 \%$ sodium dodecyl sulfate [SDS], 10\% glycerol, $100 \mathrm{mM}$ dithiothreitol [DTT], 0.1\% bromophenol blue) 24-48 h after transfection.

For immunoprecipitation, cell lysates were collected at $48 \mathrm{~h}$ post-transfection in radio immunoprecipitation assay (RIPA) buffer containing $10 \mathrm{mM}$ sodium phosphate $(\mathrm{pH} 8.0), 150 \mathrm{mM}$ $\mathrm{NaCl}, 1 \%$ Triton $\mathrm{X}-100,1 \%$ sodium deoxycholate, and $0.1 \%$ SDS in the presence of $1 \mathrm{mM}$ DTT, $1 \mathrm{mM}$ phenylmethylsulfonylfluoride (PMSF), and a protease inhibitor cocktail (PIC) (Sigma). Cell lysates were precleared with protein A beads and then incubated with either HA beads (Sigma) for ectopically expressed proteins or $1 \mu \mathrm{g}$ of antibodies against specific endogenous proteins with protein A-agarose beads on a rotator overnight at $4^{\circ} \mathrm{C}$. After three washes with RIPA buffer, immunoprecipitated complexes were eluted in sample buffer by boiling, electrophoresed through SDS-polyacrylamide gels, and subjected to immunoblot analysis.

For the in vitro pull-down assay, the purified His-tagged Nrf2 protein was incubated with the Flag-tagged wild-type or trun- 
cated forms of Hrd1 and anti-Flag M2 beads in binding buffer containing $50 \mathrm{mM}$ Tris- $\mathrm{HCl}(\mathrm{pH} 7.4), 150 \mathrm{mM} \mathrm{NaCl}, 1 \mathrm{mM}$ EDTA, and $1 \%$ Triton X-100 in the presence of $1 \mathrm{mM}$ PMSF and PIC (Sigma) on a rotator for 12 hat $4{ }^{\circ} \mathrm{C}$. After five washes with washing buffer $(50 \mathrm{mM}$ Tris- $\mathrm{HCl}, 150 \mathrm{mM} \mathrm{NaCl}, 1 \mathrm{mM}$ PMSF, $0.1 \mathrm{mM}$ PIC), complexes that were pulled down were eluted in sample buffer by boiling, electrophoresed through SDSpolyacrylamide gels, and subjected to immunoblot analysis.

\section{Luciferase reporter gene assay}

For the dual-luciferase reporter gene assay, HEK293T cells were transfected with the NQO1 ARE-luciferase plasmid along with the Renilla luciferase expression plasmid pGL4.74 (hRluc/TK) (Promega) and different amounts of expression vectors for Flag$\mathrm{XBP} 1 \mathrm{~s}$. At $24 \mathrm{~h}$ post-transfection, cells were treated with a known inducer of Nrf2, tBHQ (Sigma), for $16 \mathrm{~h}$. The transfected cells were then lysed with passive lysis buffer (Promega), and both firefly and Renilla luciferase activities were measured with the dual-luciferase reporter assay system (Promega). Firefly luciferase activity was normalized to Renilla luciferase activity. The experiment was repeated three times with triplicate samples, and the data are expressed as mean \pm standard deviation (SD).

\section{Intracellular glutathione level}

The intracellular glutathione concentration was measured using a QuantiChrom glutathione assay kit (BioAssay Systems) according to the manufacturer's instructions (Chen et al. 2009). All of the experiments were repeated three times with triplicate samples. The results are presented as mean \pm SD.

\section{NQO1 activity assay}

Cells were washed with PBS twice, harvested in $0.5 \mathrm{~mL}$ of homogenization buffer $(20 \mathrm{mM}$ Tris-HCl, $2 \mathrm{mM}$ EDTA at $\mathrm{pH}$ 7.4), and subjected to three cycles of freezing in a $-80^{\circ} \mathrm{C}$ freezer and thawing. Cell debris was removed by centrifugation at $12,000 \mathrm{~g}$ for $5 \mathrm{~min}$ at $4^{\circ} \mathrm{C}$. The supernatants were transferred to new microcentrifuge tubes for determination of protein concentration using the BCA protein assay kit (Thermo Scientific) following the manufacturer's instructions. NQO1 activity was determined by the continuous spectrophotometric assay to quantitate the dicumarol-inhibitable reduction of its substrate, DCPIP (Sigma). The rate of DCPIP reduction was monitored over $1.0 \mathrm{~min}$ at $600 \mathrm{~nm}$ with an extinction coefficient of 2.1 $\mathrm{mM}^{-1} \mathrm{~cm}^{-1}$. The NQO1 activity was calculated as the decrease in absorbance per minute per microgram of total protein of the sample in the presence or absence of the NQO1 enzyme inhibitor dicumarol (Sigma).

\section{Ubiquitylation of Nrf2}

To detect ubiquitylated Nrf2 in cultured cells, HEK293T cells transfected with expression plasmids for HA-Ub and the indicated proteins for $48 \mathrm{~h}$ were treated for $4 \mathrm{~h}$ with $10 \mu \mathrm{M}$ MG132 (Sigma) to block protein degradation. Cells were then lysed in a buffer containing $2 \%$ SDS, $150 \mathrm{mM} \mathrm{NaCl}, 10 \mathrm{mM}$ Tris- $\mathrm{HCl}$, and $1 \mathrm{mM} \mathrm{DTT}$. The cell lysates were boiled immediately for 10 min to inactivate cellular ubiquitin hydrolases to preserve ubiquitin-protein conjugates. The heated lysates were then cooled and diluted five times with a Tris-buffered salt (TBS) solution without SDS and used for immunoprecipitation with an antibody against Nrf2 (C-20) or normal rabbit IgG. Immunoprecipitated proteins were subjected to immunoblot analysis with an antibody against HA.
For ubiquitylation of Nrf2 in vitro, HEK293T cells were transfected with HA-Nrf2 and either Flag-Hrd1 or FlagHrd1(C291S). The transfected cells were lysed in lysis buffer (50 mM Tris- $\mathrm{HCl}$ at $\mathrm{pH} 7.4,150 \mathrm{mM} \mathrm{NaCl}, 1 \mathrm{mM}$ EDTA, $1 \%$ Triton X-100) containing $1 \mathrm{mM}$ DTT, $1 \mathrm{mM}$ PMSF, and protease inhibitor cocktail. The lysates were precleared with protein A beads prior to incubation with Flag M2 beads (Sigma) for $12 \mathrm{~h}$. Flag M2 beads were washed three times with TBS wash buffer $(50$ $\mathrm{mM}$ Tris- $\mathrm{HCl}, 150 \mathrm{mM} \mathrm{NaCl}$ at $\mathrm{pH}$ 7.4) containing $1 \mathrm{mM} \mathrm{DTT}$, $1 \mathrm{mM}$ PMSF, and protease inhibitor cocktail. The pellets were incubated with $300 \mathrm{pmol}$ of ubiquitin, $2 \mathrm{pmol}$ of E1, and $10 \mathrm{pmol}$ of E2-UbcH5c in $1 \times$ reaction buffer $(20 \mathrm{mM}$ Tris- $\mathrm{HCl}$ at $\mathrm{pH} 7.4$, $5 \mathrm{mM} \mathrm{MgCl}_{2}, 2 \mathrm{mM} \mathrm{ATP}$ ) in a total volume of $40 \mu \mathrm{L}$ for $90 \mathrm{~min}$ at $37^{\circ} \mathrm{C}$. Ubiquitin, $\mathrm{E} 1$, and $\mathrm{E} 2-\mathrm{UbcH} 5 \mathrm{c}$ were purchased from Boston Biochem. The Flag M2 was centrifuged at $3000 \mathrm{~g}$, and the pellets were resuspended in $2 \%$ SDS, and $150 \mathrm{mM}$ Tris- $\mathrm{HCl}$ $(\mathrm{pH} 8.0)$ and boiled for $5 \mathrm{~min}$ to release bound proteins and disrupt protein-protein interactions. The supernatant was diluted with buffer lacking SDS prior to immunoprecipitation with anti-Nrf2 antibodies. Immunoprecipitated proteins were subjected to immunoblot analysis with anti-ubiquitin antibodies.

\section{Protein half-life measurement}

To measure the half-life of Nrf2, $50 \mu \mathrm{M}$ cycloheximide (Sigma) was added to block protein synthesis. Total cell lysates were collected at different time points and subjected to immunoblot analysis with anti-Nrf2 and anti-tubulin antibodies. The intensity of the bands was quantified using the ChemiDoc CRS gel documentation system and Quantity One software (Bio-Rad). Relative intensity (Nrf2 vs. tubulin) was plotted using a semilogarithmic scale.

\section{Protein radiolabeling and in vitro binding assay}

Hrd1-WT and its mutants were radiolabeled with $\left[{ }^{35} \mathrm{~S}\right]$ methionine using the in vitro TNT Quick PCR transcription/translation system (Promega). GST-tagged Nrf2 and domain deletion proteins were expressed in Escherichia coli Rosetta (DE3) LysS cells and purified with glutathione sepharose $4 \mathrm{~B}$ matrix (Amersham Biosciences). For the in vitro binding assay, radiolabeled proteins and purified proteins were incubated in binding buffer $14.2 \mathrm{mM}$ $\mathrm{Na}_{2} \mathrm{HPO}_{4}, 2 \mathrm{mM} \mathrm{KHPO}, 140 \mathrm{mM} \mathrm{NaCl}, 10 \mathrm{mM} \mathrm{KCl}, 0.2 \%$ bovine serum albumin [BSA], 0.02\% Triton X-100, $1 \mathrm{mM}$ DTT) in the presence of sepharose beads for $4-6 \mathrm{~h}$ at $4^{\circ} \mathrm{C}$. The beads were then washed six times with binding buffer. The proteins were eluted by boiling in SDS sample buffer followed by SDSPAGE and autoradiography analysis.

\section{Fluorescently tagged proteins and immunofluorescence}

Cells were grown on 35-mm glass-bottom dishes (In Vivo Scientific) for live-cell imaging. Cells were transfected with the indicated fluorescent-labeled proteins. At $24 \mathrm{~h}$ post-transfection, the medium was replaced with phenol red-free DMEM supplemented with $10 \%$ FBS. All images were taken with the Zeiss Observer using the Slidebook 4.2.0.11 computer program (Intelligent Imaging Innovations, Inc.).

\section{$m R N A$ extraction and quantitative real-time PCR (qRT-PCR)}

Total mRNA was extracted from cells using TRI reagent (Sigma). Equal amounts of RNA were used for reverse transcription using a Transcriptor first strand cDNA synthesis kit (Roche). The following TaqMan probes from the universal probe library 
(Roche) were used: human Nrf2 (no.70), human NQO1 (no. 87), human HO-1 (no. 25), human Hrd1 (no. 25), human GAPDH (no. 25), mouse Nrf2 (no. 56), mouse Hrd1 (no. 2), mouse NQO1 (no. 50), mouse HO-1 (no. 25), and mouse $\beta$-actin (no. 56). The following primers were synthesized by Integrated DNA Technologies: hNrf2, forward (5'-ACACGGTCCACAGCTCATC-3') and reverse (5'-TGTCAATCAAATCCATGTCCTG-3'); hNQO1, forward ( $5^{\prime}$-ATGTATGACAAAGGACCCTTCC-3') and reverse (5'-TCCCTTGCAGAGAGTACATGG-3'); hHO-1, forward (5'AACTTTCAGAAGGGCCAGGT- ${ }^{\prime}$ ) and reverse (5'-CTGGG CTCTCCTTGTTGC-3'); hHrd1, forward (5'-CCAGTACCTC ACCGTGCTG-3') and reverse (5'-GCCTCTGAGCTAGGGA TGC- $\left.3^{\prime}\right)$; hGAPDH, forward (5'-CTGACTTCAACAGCGAC ACC-3') and reverse (5'-TGCTGTAGCCAAATTCGTTGT-3'); mNrf2, forward (5'-TTTTCCATTCCCGAATTACAGT-3') and reverse (5'-AGGAGATCGATGAGTAAAAATGGT-3'); and mNQO1, forward (5' -AGGGTTCGGTATTACGATCC-3') and reverse $\left(5^{\prime}\right.$-AGTACAATCAGGGCTCTTCTCG-3'). qRT-PCR was performed on the LightCycler 480 system (Roche) as follows: one cycle of initial denaturation $\left(4 \mathrm{~min}\right.$ at $\left.95^{\circ} \mathrm{C}\right), 45$ cycles of amplification $\left(10 \mathrm{sec}\right.$ at $95^{\circ} \mathrm{C}$ and $30 \mathrm{sec}$ at $60^{\circ} \mathrm{C}$ ), and a cooling period. The data presented are relative mRNA levels normalized to the level of GAPDH, and the value from the untreated cells was set as 1 . PCR assays were performed three times with duplicate samples, which were used to determine the means \pm standard deviations. Student's $t$-test was used to evaluate statistically significant differences.

\section{XBP1 splicing assay}

The XBP1 splicing assay was performed as previously described (Calfon et al. 2002). In brief, RNA from $X B P 1^{+/+}$and $X B P 1^{-/-}$ MEF cells were reverse-transcribed, followed by PCR using the sense primer (5'-AAACAGAGTAGCAGCGCAGACTGC-3') and the antisense primer $\left(5^{\prime}\right.$-TCCTTCTGGGTAGACCTCTGG GAG-3'). PCR products were resolved on $2.5 \%(\mathrm{w} / \mathrm{v})$ agarose gels, stained with ethidium bromide, and visualized.

\section{Analysis of lipid peroxidation}

Liver samples were analyzed in an indirect assessment for lipid peroxidation using the thiobarbituric acid-reactive substances (TBARS) assay kit (Cayman Chemical). Liver samples were homogenized in RIPA buffer $(50 \mathrm{mM}$ Tris- $\mathrm{HCl}$ at $\mathrm{pH} 7.6$, containing $150 \mathrm{mM}$ sodium chloride, $1 \%$ NP-40, $0.5 \%$ sodium deoxycholate, $0.1 \%$ SDS) with protease inhibitors. The assay was then carried out according to the manufacturer's instructions and analyzed by reading absorbance at $540 \mathrm{~nm}$.

\section{Terminal dUTP nick end-labeling (TUNEL) staining}

Apoptotic cell death in liver tissues was detected using TUNEL, an in situ cell death detection kit (Roche), according to the manufacturer's instruction. Images were taken using a fluorescence microscope (Zeiss Observer Z1, Marianas digital microscopy workstation).

\section{Statistical analysis}

Data are presented as means \pm SD. Differences were determined by two-tailed Student's $t$-test. A $P$-value $<0.05$ was considered significant.

\section{Acknowledgments}

This study was funded by ES015010 and CA154377 (to D.D.Z.), AI079056 (to D.F.), and ES006694 (a center grant).

\section{References}

Amano T, Yamasaki S, Yagishita N, Tsuchimochi $\mathrm{K}$, Shin $\mathrm{H}$, Kawahara K, Aratani S, Fujita H, Zhang L, Ikeda R, et al. 2003. Synoviolin/Hrd1, an E3 ubiquitin ligase, as a novel pathogenic factor for arthropathy. Genes Dev 17: 2436-2449.

Calfon M, Zeng H, Urano F, Till JH, Hubbard SR, Harding HP, Clark SG, Ron D. 2002. IRE1 couples endoplasmic reticulum load to secretory capacity by processing the XBP-1 mRNA. Nature 415: 92-96.

Carvalho P, Goder V, Rapoport TA. 2006. Distinct ubiquitinligase complexes define convergent pathways for the degradation of ER proteins. Cell 126: 361-373.

Chen W, Sun Z, Wang XJ, Jiang T, Huang Z, Fang D, Zhang DD. 2009. Direct interaction between Nrf2 and p21(Cip1/WAF1) upregulates the Nrf2-mediated antioxidant response. Mol Cell 34: 663-673.

Chen S, Zou L, Li L, Wu T. 2013. The protective effect of glycyrrhetinic acid on carbon tetrachloride-induced chronic liver fibrosis in mice via upregulation of Nrf2. PLOS ONE 8: e53662.

Chowdhry S, Zhang Y, McMahon M, Sutherland C, Cuadrado A, Hayes JD. 2013. Nrf2 is controlled by two distinct $\beta$-TrCP recognition motifs in its Neh6 domain, one of which can be modulated by GSK-3 activity. Oncogene 32: 3765-3781.

Cross BC, Bond PJ, Sadowski PG, Jha BK, Zak J, Goodman JM, Silverman RH, Neubert TA, Baxendale IR, Ron D, et al. 2012. The molecular basis for selective inhibition of unconventional mRNA splicing by an IRE1-binding small molecule. Proc Natl Acad Sci 109: E869-E878.

Gao B, Lee SM, Chen A, Zhang J, Zhang DD, Kannan K, Ortmann RA, Fang D. 2008. Synoviolin promotes IRE1 ubiquitination and degradation in synovial fibroblasts from mice with collagen-induced arthritis. EMBO Rep 9: 480-485.

Hasegawa D, Fujii R, Yagishita N, Matsumoto N, Aratani S, Izumi T, Azakami K, Nakazawa M, Fujita H, Sato T, et al. 2010. E3 ubiquitin ligase synoviolin is involved in liver fibrogenesis. PLOS ONE 5: e13590.

Hernandez-Gea V, Friedman SL. 2011. Pathogenesis of liver fibrosis. Annu Rev Pathol 6: 425-456.

Itoh K, Wakabayashi N, Katoh Y, Ishii T, Igarashi K, Engel JD, Yamamoto M. 1999. Keap1 represses nuclear activation of antioxidant responsive elements by Nrf2 through binding to the amino-terminal Neh2 domain. Genes Dev 13: 76-86.

Jaramillo MC, Zhang DD. 2013. The emerging role of the Nrf2Keap1 signaling pathway in cancer. Genes Dev 27: 21792191.

Jiang T, Huang Z, Chan JY, Zhang DD. 2009. Nrf2 protects against As(III)-induced damage in mouse liver and bladder. Toxicol Appl Pharmacol 240: 8-14.

Kawata K, Kobayashi Y, Souda K, Kawamura K, Sumiyoshi S, Takahashi Y, Noritake H, Watanabe S, Suehiro T, Nakamura H. 2010. Enhanced hepatic Nrf2 activation after ursodeoxycholic acid treatment in patients with primary biliary cirrhosis. Antioxid Redox Signal 13: 259-268.

Kensler TW, Wakabayashi N, Biswal S. 2007. Cell survival responses to environmental stresses via the Keap1-Nrf2ARE pathway. Annu Rev Pharmacol Toxicol 47: 89-116.

Kobayashi A, Kang MI, Okawa H, Ohtsuji M, Zenke Y, Chiba T, Igarashi K, Yamamoto M. 2004. Oxidative stress sensor Keap1 functions as an adaptor for Cul3-based E3 ligase to regulate proteasomal degradation of Nrf2. Mol Cell Biol 24: 7130-7139.

Kurzawski M, Dziedziejko V, Urasinska E, Post M, Wojcicki M, Mietkiewski J, Drozdzik M. 2012. Nuclear factor erythroid 2-like 2 (Nrf2) expression in end-stage liver disease. Environ Toxicol Pharmacol 34: 87-95. 
Lotersztajn S, Julien B, Teixeira-Clerc F, Grenard P, Mallat A. 2005. Hepatic fibrosis: molecular mechanisms and drug targets. Annu Rev Pharmacol Toxicol 45: 605-628.

Ma Q, He X. 2012. Molecular basis of electrophilic and oxidative defense: promises and perils of Nrf2. Pharmacol Rev 64: $1055-1081$.

Magesh S, Chen Y, Hu L. 2012. Small molecule modulators of Keap1-Nrf2-ARE pathway as potential preventive and therapeutic agents. Med Res Rev 32: 687-726.

McMahon M, Thomas N, Itoh K, Yamamoto M, Hayes JD. 2006. Dimerization of substrate adaptors can facilitate cullinmediated ubiquitylation of proteins by a 'tethering' mechanism: a two-site interaction model for the Nrf2-Keap1 complex. J Biol Chem 281: 24756-24768.

More VR, Cheng Q, Donepudi AC, Buckley DB, Lu ZJ, Cherrington NJ, Slitt AL. 2013. Alcohol cirrhosis alters nuclear receptor and drug transporter expression in human liver. Drug Metab Dispos 41: 1148-1155.

Mu YP, Ogawa T, Kawada N. 2010. Reversibility of fibrosis, inflammation, and endoplasmic reticulum stress in the liver of rats fed a methionine-choline-deficient diet. Lab Invest 90: $245-256$

Nair S, Xu C, Shen G, Hebbar V, Gopalakrishnan A, Hu R, Jain MR, Liew C, Chan JY, Kong AN. 2007. Toxicogenomics of endoplasmic reticulum stress inducer tunicamycin in the small intestine and liver of Nrf2 knockout and C57BL/6J mice. Toxicol Lett 168: 21-39.

Qiu Q, Zheng Z, Chang L, Zhao YS, Tan C, Dandekar A, Zhang Z, Lin Z, Gui M, Li X, et al. 2013. Toll-like receptor-mediated IRE $1 \alpha$ activation as a therapeutic target for inflammatory arthritis. EMBO I 32: 2477-2490.

Rada P, Rojo AI, Chowdhry S, McMahon M, Hayes JD, Cuadrado A. 2011. SCF $/ \beta$-TrCP promotes glycogen synthase kinase 3-dependent degradation of the Nrf2 transcription factor in a Keapl-independent manner. Mol Cell Biol 31: 1121-1133.

Rada P, Rojo AI, Evrard-Todeschi N, Innamorato NG, Cotte A, Jaworski T, Tobon-Velasco JC, Devijver H, Garcia-Mayoral MF, Van Leuven F, et al. 2012. Structural and functional characterization of Nrf2 degradation by the glycogen synthase kinase 3/ $\beta$-TrCP axis. Mol Cell Biol 32: 3486-3499.

Ramani K, Tomasi ML, Yang H, Ko K, Lu SC. 2012. Mechanism and significance of changes in glutamate-cysteine ligase expression during hepatic fibrogenesis. I Biol Chem 287: 36341-36355.

Steffen J, Seeger M, Koch A, Kruger E. 2010. Proteasomal degradation is transcriptionally controlled by TCF11 via an ERAD-dependent feedback loop. Mol Cell 40: 147-158.

Sun Z, Zhang S, Chan JY, Zhang DD. 2007. Keap1 controls postinduction repression of the Nrf2-mediated antioxidant response by escorting nuclear export of Nrf2. Mol Cell Biol 27: 6334-6349.

Sun Z, Chin YE, Zhang DD. 2009. Acetylation of Nrf2 by p300/ CBP augments promoter-specific DNA binding of Nrf2 during the antioxidant response. Mol Cell Biol 29: 2658-2672.

Sykiotis GP, Bohmann D. 2010. Stress-activated cap'n'collar transcription factors in aging and human disease. Sci Signal 3: re3.

Tanabe C, Maeda T, Zou K, Liu J, Liu S, Nakajima T, Komano H. 2012. The ubiquitin ligase synoviolin up-regulates amyloid $\beta$ production by targeting a negative regulator of $\gamma$-secretase, Rer1, for degradation. J Biol Chem 287: 44203-44211.

Tong KI, Kobayashi A, Katsuoka F, Yamamoto M. 2006. Twosite substrate recognition model for the Keap1-Nrf2 system: a hinge and latch mechanism. Biol Chem 387: 1311-1320.

Travers KJ, Patil CK, Wodicka L, Lockhart DJ, Weissman JS, Walter P. 2000. Functional and genomic analyses reveal an essential coordination between the unfolded protein response and ER-associated degradation. Cell 101: 249-258.

Tsang KY, Chan D, Bateman JF, Cheah KS. 2010. In vivo cellular adaptation to ER stress: survival strategies with doubleedged consequences. J Cell Sci 123: 2145-2154.

Tsuchiya Y, Morita T, Kim M, Iemura S, Natsume T, Yamamoto M, Kobayashi A. 2011. Dual regulation of the transcriptional activity of Nrf1 by $\beta$-TrCP- and Hrd1-dependent degradation mechanisms. Mol Cell Biol 31: 4500-4512.

Wang JQ, Chen X, Zhang C, Tao L, Zhang ZH, Liu XQ, Xu YB, Wang H, Li J, Xu DX. 2013. Phenylbutyric acid protects against carbon tetrachloride-induced hepatic fibrogenesis in mice. Toxicol Appl Pharmacol 266: 307-316.

Wynn TA, Ramalingam TR. 2012. Mechanisms of fibrosis: therapeutic translation for fibrotic disease. Nat Med 18: 1028-1040.

Yagishita N, Ohneda K, Amano T, Yamasaki S, Sugiura A, Tsuchimochi K, Shin H, Kawahara K, Ohneda O, Ohta T, et al. 2005. Essential role of synoviolin in embryogenesis. I Biol Chem 280: 7909-7916.

Yagishita N, Aratani S, Leach C, Amano T, Yamano Y, Nakatani K, Nishioka K, Nakajima T. 2012. RING-finger type E3 ubiquitin ligase inhibitors as novel candidates for the treatment of rheumatoid arthritis. Int J Mol Med 30: 1281-1286.

Yamamoto K, Suzuki N, Wada T, Okada T, Yoshida H, Kaufman RJ, Mori K. 2008. Human HRD1 promoter carries a functional unfolded protein response element to which XBP1 but not ATF6 directly binds. J Biochem 144: 477-486.

Yamasaki S, Yagishita N, Sasaki T, Nakazawa M, Kato Y, Yamadera T, Bae E, Toriyama S, Ikeda R, Zhang L, et al. 2007. Cytoplasmic destruction of p53 by the endoplasmic reticulum-resident ubiquitin ligase 'synoviolin'. EMBO I 26: 113-122.

Yoshida H, Matsui T, Yamamoto A, Okada T, Mori K. 2001. XBP1 mRNA is induced by ATF6 and spliced by IRE1 in response to ER stress to produce a highly active transcription factor. Cell 107: 881-891.

Zhang DD, Hannink M. 2003. Distinct cysteine residues in Keap1 are required for Keap1-dependent ubiquitination of Nrf2 and for stabilization of Nrf2 by chemopreventive agents and oxidative stress. Mol Cell Biol 23: 8137-8151.

Zhang DD, Lo SC, Cross JV, Templeton DJ, Hannink M. 2004. Keap1 is a redox-regulated substrate adaptor protein for a Cul3-dependent ubiquitin ligase complex. Mol Cell Biol 24: 10941-10953.

Zhang Y, Crouch DH, Yamamoto M, Hayes JD. 2006. Negative regulation of the Nrf1 transcription factor by its $\mathrm{N}$-terminal domain is independent of Keap1: Nrf1, but not Nrf2, is targeted to the endoplasmic reticulum. Biochem J 399: 373385.

Zheng H, Whitman SA, Wu W, Wondrak GT, Wong PK, Fang D, Zhang DD. 2011a. Therapeutic potential of Nrf2 activators in streptozotocin-induced diabetic nephropathy. Diabetes 60: $3055-3066$

Zheng Z, Zhang C, Zhang K. 2011b. Measurement of ER stress response and inflammation in the mouse model of nonalcoholic fatty liver disease. Methods Enzymol 489: 329-348. 


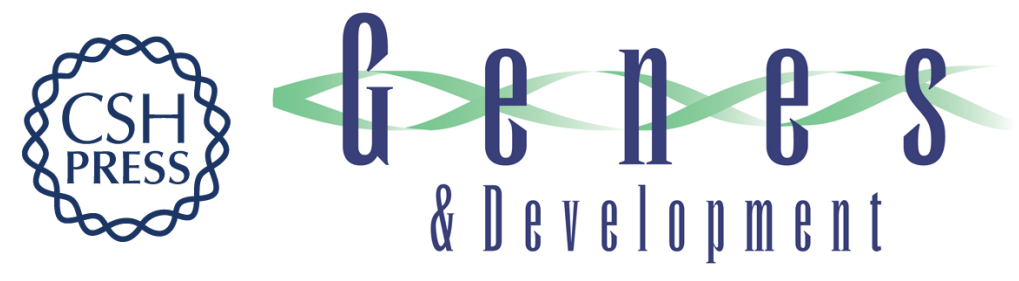

\section{Hrd1 suppresses Nrf2-mediated cellular protection during liver cirrhosis}

Tongde Wu, Fei Zhao, Beixue Gao, et al.

Genes Dev. 2014, 28: originally published online March 17, 2014

Access the most recent version at doi:10.1101/gad.238246.114

\section{Supplemental http://genesdev.cshlp.org/content/suppl/2014/03/11/gad.238246.114.DC1 Material}

References This article cites 49 articles, 25 of which can be accessed free at: http://genesdev.cshlp.org/content/28/7/708.full.html\#ref-list-1

Creative This article is distributed exclusively by Cold Spring Harbor Laboratory Press for the first Commons six months after the full-issue publication date (see

License http://genesdev.cshlp.org/site/misc/terms.xhtml). After six months, it is available under a Creative Commons License (Attribution-NonCommercial 4.0 International), as described at http://creativecommons.org/licenses/by-nc/4.0/.

Email Alerting Receive free email alerts when new articles cite this article - sign up in the box at the top Service right corner of the article or click here.

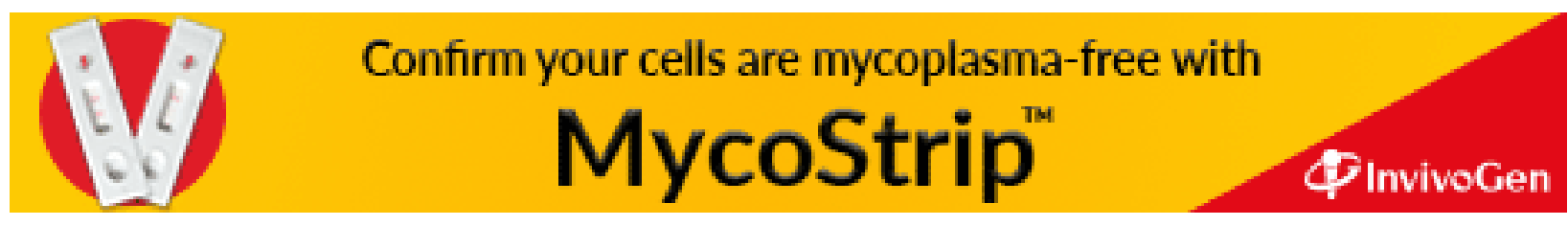

